\title{
Thermodynamic equilibrium and kinetic fundamentals of oxide dissolution in aqueous solution
}

\author{
Jianwei Wang ${ }^{1, a)}$ (1) \\ ${ }^{1}$ Department of Geology and Geophysics, Center for Computation and Technology, Louisiana State University, Baton Rouge, \\ Louisiana 70803, USA \\ ${ }^{a}$ Address all correspondence to this author. e-mail: jianwei@lsu.edu \\ Received: 2 November 2019; accepted: 27 March 2020
}

Dissolution of oxides in aqueous solutions is fundamentally important for a range of applications and a critical process that determines the chemical durability of industrial ceramics, the performance of nuclear waste forms, and the chemical weathering of minerals. The thermodynamic equilibrium and kinetics of dissolution reactions are key to determining the rate at which oxides dissolve. The increase in collaborative research across disciplines in materials research necessitates a common background to tackle shared scientific problems across different fields. This review selectively examines the fundamentals of dissolution theories that have been developed in chemistry, geochemistry, and materials science, and assembles them into a single collective document for the broader materials science community. Applications of the theories are highlighted using examples from specific areas, but can be similarly applied to other areas. Challenges and future research needs for a predictive-level understanding are discussed in light of the current literature.

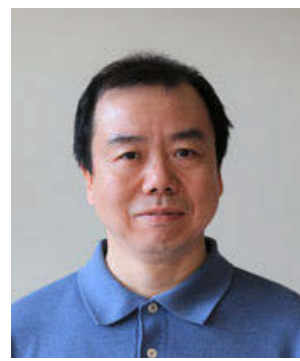

Jianwei Wang

Dr. Jianwei Wang is an Associate Professor in the Department of Geology and Geophysics at Louisiana State University. He received his Ph.D. from University of Illinois at Urbana-Champaign in Earth Materials and Geochemistry. Prior to joining Louisiana State University, Dr. Wang was a Postdoctoral Research Associate and then Assistant Research Scientist at University of California at Davis and University of Michigan. His research spans from water-rock interactions and dissolution of minerals and ceramics in Environmental Geochemistry, high pressure of materials and liquid alloys in Mineral Physics, and irradiation effect and nuclear waste forms in Nuclear Energy. Dr. Wang is specialized in atomistic scale modeling and electronic structure calculations of the materials using high-performance computers. His research focuses on the understanding of the structure and property relationship of materials for energy and environmental applications. Using theory, computation, and experiment, Dr. Wang with his research group is currently developing methods to predict the long-term dissolution rate of ceramics in the environment and effect of light elements on physical properties of liquid iron-nickel alloy in the Earth's outer core.

\section{Introduction}

The thermodynamic equilibrium and kinetics of oxide dissolution reactions determine their chemical durability in aqueous solutions. The rate at which these materials dissolve into the environment is of great interest in a range of applications, such as the synthesis and performance of ceramics, reactive transport of contaminants, carbon sequestration, nuclear waste disposal, and chemical weathering. For industrial materials, environmental weathering leads to concerns related to safety and efficiency and value losses. In the subsurface environment, mineral dissolution affects the reactive transport of natural and man-made contaminants, the performance of a nuclear waste repository, and carbon dioxide sequestration in a geological formation. In the Earth's surface environment, geochemical weathering of the continental crust has a dominant role in the balance of carbon dioxide in the atmosphere, elemental cycling on the Earth's surface, the formation of soils, and the chemical evolution of the ocean. For all these applications, a prediction of the rate at which oxides dissolve is essential. Therefore, a predictive understanding of the dissolution rate of these materials is critical for their applications.

Prediction of the dissolution rate of a material requires a quantitative understanding of the correlations between the environment and the properties of the material. The environment 
is defined by variables including temperature, pressure, and solution chemistry. The properties refer to those related to chemical durability that are intrinsic to the material and are not affected by environmental variables. Complex interactions between the intrinsic properties and environmental variables make rate prediction challenging. First, depending on the application, the timescale of interest can be as much as millions of years in chemical weathering and nuclear waste disposal, as short as minutes in the cold sintering synthesis of ceramics, or even seconds in the fracturing of the rocks during an active earthquake. This creates a great difficulty in understanding dissolution kinetics because the dissolution rates are not constant and may change over time. The rates are highly dependent on the environmental conditions and the materials themselves, and both of them may change or transform as a function of time. This makes the understanding of the mechanisms critically important. Fundamentally, dissolution reactions of oxides are complex chemical reactions that consist of parallel and sequential elementary reactions, such as solvation, surface complexation, hydrolysis, and detachment of surface-activated complexes. Not all these reactions determine the overall dissolution rate. The rate determining steps are often related to surface complexes, which are often hypothesized and difficult to probe and identify directly. These surface reactions are indirectly related to the crystal bulk properties through the interface. Such an indirect relationship between the dissolution rate and the bulk properties and solution conditions complicates the prediction of dissolution kinetics. In addition, there are many parameters to be considered, including those intrinsic to the material, such as the structure and composition, the presence of defects and impurities, radiation damage, and the microstructure, and those environmental controlling variables, such as temperature, pressure, $\mathrm{pH}$, redox potential, and composition of the solution. These challenges create great opportunities for interdisciplinary research where fundamental principles would be used to build predictive models to understand oxide dissolutions for various applications with focuses on different time and length scales.

In addition to those challenges that are common to all oxides, different applications add their specific complexities. For instance, for nuclear waste development, the waste elements to be immobilized span the whole periodic table and include alkali and alkaline earth elements, halogens, transition metals, rare earth elements, and actinides [1]. Great efforts have been made to incorporate as many waste elements as possible into one waste form for simplicity and cost-effectiveness using materials such as borosilicate glass, concrete and cement composites, titanate-based ceramics, and phosphatebased ceramics, to name a few [2]. This leads to a unique challenge in understanding the dissolution of the resulting waste forms in the environment. Because each group of elements has unique and dramatically different chemistry, they react with water differently. Some elements are highly soluble in water, and others are insoluble, which leads to complex dissolution behavior for multiple metal oxides. In addition, because nuclear waste forms need to be isolated from the environment for hundreds of thousands of years, prediction of the long-term dissolution rate requires an understanding of the mechanisms of all critical rate-determining reactions. Thermodynamic equilibrium and kinetic theories of dissolution reactions can provide the foundation for predicting long-term chemical durability in the environment.

The purpose of this review is to selectively summarize some thermodynamic equilibrium and kinetics theories that are useful for a predictive understanding of the dissolution of oxides in aqueous environments. These theories have been developed and used in the past decades for understanding dissolution behavior and modeling experimental and field observations. Some applications of the theories are highlighted using examples from a number of fields with specific applications. In this review, the chemical durability of a material is characterized by a number of properties including its solubility, dissolution rate constant at far-from-equilibrium, how the dissolution rate changes with the saturation conditions, and the effects of $\mathrm{pH}$ and temperature. Examples and discussions are more weighted toward complex oxides with multiple metals having significant different chemical bondings such as metal oxide silicates. These complex materials are not only intriguing in terms of the dissolution mechanism but also have practical applications. Challenges and opportunities for a predictive understanding of dissolution kinetics are discussed within the current literature. There are a number of previous reviews in the literature that are valuable for understanding oxide dissolution $[1,3,4,5,6,7,8,9,10]$. The present review is intended to be complementary to those previous ones and in a more compact style. A comprehensive review is not intended. Topics not covered in this review include dissolutions involving redox reactions, dissolutions under an external field, dissolutions in a confined space, and dissolutions promoted by organic ligands and bioactivities, which deserve their own separate reviews.

\section{Effect of the composition of oxides on chemical durability}

The chemical durability of oxides can be qualitatively understood from the properties of the constituent elements. Because elements belonging to the same group in the periodic table have similar chemical reactivities, the chemical durability and speciation in aqueous solutions can be understood from well-studied elements in the same group. For instance, halogen ions such as chloride and iodide occupy a large area in the Eh$\mathrm{pH}$ diagram under conditions that commonly occur in natural environments. They do not react strongly with many common 
aqueous species and rocks in the environment. Therefore, they are highly soluble and mobile. Rare earth elements often form trivalent cations with a relatively strong covalent bonding character in oxides, which makes them relatively less soluble in aqueous solutions than alkali and alkaline earth oxides. The bonding character in oxides can be qualitatively estimated using the basic properties of the element, such as the electronegativity and formal charge. Elements that tend to form a strong covalent bond with oxygen often form oxyanions as a structural rigid unit in oxide or aqueous solutions. Oxyanions with a high nominal charge, such as $\left[\mathrm{BO}_{4}{ }^{5-}\right],\left[\mathrm{AlO}_{4}{ }^{5-}\right]$, $\left[\mathrm{SiO}_{4}{ }^{4-}\right]$, and $\left[\mathrm{PO}_{4}{ }^{3-}\right]$, often participate in the structural network of oxides. Oxyanions with a low nominal charge, such as $\left[\mathrm{ClO}_{4}{ }^{1-}\right],\left[\mathrm{TcO}_{4}{ }^{1-}\right],\left[\mathrm{IO}_{3}{ }^{1-}\right],\left[\mathrm{SeO}_{4}{ }^{2-}\right],\left[\mathrm{SO}_{4}{ }^{2-}\right]$, and $\left[\mathrm{CrO}_{4}{ }^{2-}\right]$, are often not structurally compatible with the structural network of the highly charged oxyanions in oxides, and thus tend to form ionic units in the oxide and are highly soluble in aqueous solutions. For instance, in boroaluminosilicate glass, $\left[\mathrm{BO}_{4}{ }^{5-}\right],\left[\mathrm{AlO}_{4}{ }^{5-}\right]$, and $\left[\mathrm{SiO}_{4}{ }^{4-}\right]$ oxyanions participate in the network structure of the glass with networkmodifier cations to balance the charge. Oxyanions such as $\left[\mathrm{SO}_{4}{ }^{2-}\right]$ do not participate in the framework and have low solubility in the glass. For crystalline aluminosilicates such as zeolite, low charge oxyanions can only be incorporated into the cages of the structure, which are not part of the network structure.

For redox-sensitive elements, their properties, such as solubility in oxides and aqueous solution, are strongly affected by their oxidation state, which is controlled by the oxygen fugacity during the synthesis of the oxide and the redox potential in the aqueous solution respectively. For instance, the solubility of ferrous iron in solution is greatly reduced as a result of an increase in the oxidation state from $\mathrm{Fe}^{2+}$ to $\mathrm{Fe}^{3+}$. Oxides of $\mathrm{Tc}^{7+}$ are highly soluble in aqueous solutions, whereas oxides of $\mathrm{Tc}^{4+}$ are more durable with a much lower solubility. Oxidizing $\mathrm{Cr}^{3+}$ to $\mathrm{Cr}^{6+}$ changes its speciation in solution from $\mathrm{Cr}^{3+}$ or $\mathrm{Cr}(\mathrm{OH})_{3}{ }^{0}$ to $\mathrm{HCrO}_{4}{ }^{1-}$ or $\mathrm{CrO}_{4}{ }^{2-}$, which dramatically increases its solubility in oxidized aqueous solutions. Similarly, oxidizing $\mathrm{U}^{4+}$ to $\mathrm{U}^{6+}$ changes the speciation of $\mathrm{U}^{4+}$ or $\mathrm{U}(\mathrm{OH})_{4}{ }^{0}$ to $\mathrm{UO}_{2}{ }^{2+}$ or $\mathrm{UO}_{2}(\mathrm{OH})_{2}{ }^{0}$, which significantly increases the solubility of uranium in aqueous solutions. Oxidation of $\mathrm{Se}^{4+}$ to $\mathrm{Se}^{6+}$ has a similar effect on the solubility in aqueous solution. Because of the significant change of the solubility in aqueous solutions as a result of changes in the oxidation state, the redox potential becomes an important environmental variable that affects the dissolution rate of oxides with redox-sensitive elements. Dissolutions of these materials have been reviewed elsewhere [11, 12] and highlighted in a number of studies [13, 14, 15, 16, 17]. Taking advantage of the solubility changes, chemical reducing agents and reduced geological formations have been used as remediation strategies to control the transport of some containments in the environment $[18,19,20,21]$. On the other hand, redox reaction-induced dissolution can cause contaminations such as arsenic in the environment $[22,23]$.

The ionic potential of an element, a property derived from the formal charge and ionic radius [24], is defined as $z / r$, where $z$ is the formal charge and $r$ is the ionic radius. The ionic potential has been used to understand the reactivity of ions in oxides and aqueous solutions [25, 26, 27]. A higher ionic potential of an ion results in more covalent bonding to oxygen in the oxide; stronger interactions with water, aqueous species, and surfaces; and a lower oxide dissolution rate. Thus, the ionic potential of elements has been generally used to understand the reactivity of aqueous species, the solubility of oxides in aqueous solutions, and the dissolution rate for a range of oxides. For highly ionic systems, the ionic potential has been used to quantitatively understand the chemical reactivity of oxides and aqueous species such as the water-ligand exchange of metal solvation complexes [28]. For more covalent systems, the ionic potential has been used as a qualitative indicator because other factors such as molecular orbital interactions play a role as well. For instance, ferric iron $\left(\mathrm{Fe}^{3+}\right)$ oxides have a much lower solubility than ferrous iron $\left(\mathrm{Fe}^{2+}\right)$ at a given $\mathrm{pH}$ and redox potential as a result of the higher ionic potential of ferric iron. For apatite, experimental results show that the dissolution rate of natural apatite $\left(\mathrm{Ca}_{10}\left(\mathrm{PO}_{4}\right)_{6} \mathrm{~F}_{2}\right)$ is approximately 3 orders of magnitude lower than that of synthetic iodoapatite $\left(\mathrm{Pb}_{10}\left(\mathrm{VO}_{4}\right)\right.$ ${ }_{6} \mathrm{I}_{2}$ ) with the same structure at a given temperature and $\mathrm{pH}$. The activation energy for the dissolution of natural apatite is more than 2 times that of iodoapatite [29, 30,31]. The higher ionic potentials of the constituent elements in natural apatite lead to shorter bond distances and stronger chemical bonding with respect to iodoapatite, which result in a higher activation energy and lower dissolution rate for fluorapatite than iodoapatite [31]. For borosilicate glass, the network structure is mainly composed of high nominal charge oxyanions such as $\left[\mathrm{SiO}_{4}{ }^{4-}\right],\left[\mathrm{BO}_{3}{ }^{3-}\right],\left[\mathrm{BO}_{4}{ }^{5-}\right]$, and $\left[\mathrm{AlO}_{4}{ }^{5-}\right]$. Low ionic potential anions such as $\mathrm{I}^{-}$and $\mathrm{Cl}^{-}$, as well as low nominal charge oxyanion units such as $\left[\mathrm{IO}_{3}{ }^{1-}\right], \quad\left[\mathrm{TcO}_{4}{ }^{1-}\right], \quad\left[\mathrm{ClO}_{4}{ }^{1-}\right]$, $\left[\mathrm{MoO}_{4}{ }^{2-}\right],\left[\mathrm{CrO}_{4}{ }^{2-}\right]$, and $\left[\mathrm{SO}_{4}{ }^{2-}\right]$, are incompatible with the network structure of borosilicate glass, leading to their low solubility in glass [32].

\section{Effect of the structure of oxides on chemical durability}

The chemical durability of oxides can also be qualitatively understood based on their structure. One of the important structural characteristics that affect durability is the connectivity of the covalently bonded units in multiple-metal oxides. In silicates, the extended structure of the $\left[\mathrm{SiO}_{4}\right]$ tetrahedral 
network has an important effect on the chemical durability. The dissolution rate decreases as the connectedness of the $\left[\mathrm{SiO}_{4}\right]$ tetrahedral units increases $[9,10]$. As shown in Fig. 1, nesosilicates (orthosilicates) such as Ca-olivine $\left(\mathrm{Ca}_{2} \mathrm{SiO}_{4}\right)$ with isolated silicate tetrahedrons [i.e., each $\left(\mathrm{SiO}_{4}\right)$ tetrahedron has a central silicon atom surrounded by four oxygen atoms at the corners that do not share with any other $\left(\mathrm{SiO}_{4}\right)$ tetrahedron] have the highest dissolution rate among different groups of silicate minerals. With the same crystal structure, the effect of the composition is highlighted by forsterite $\left(\mathrm{Mg}_{2} \mathrm{SiO}_{4}\right)$, which has a dissolution rate over 3 orders of magnitude lower over a range of $\mathrm{pH}$ values than Ca-olivine. The ionic potential of $\mathrm{Mg}^{2+}$ is $\sim 26 \%$ higher than that of $\mathrm{Ca}^{2+}$ ions $[9,10]$. Inosilicates such as wollastonite $\left(\mathrm{CaSiO}_{3}\right)$, enstatite $\left(\mathrm{MgSiO}_{3}\right)$, and diopside $\left(\mathrm{MgCaSi}_{2} \mathrm{O}_{6}\right)$ are single chain silicates with interlocking chains of silicate tetrahedrons and have a much lower dissolution rate, for example, $\sim 3$ orders of magnitude lower for $\mathrm{CaSiO}_{3}$ than $\mathrm{Ca}_{2} \mathrm{SiO}_{4}$. Minerals such as chrysotile $\left(\mathrm{Mg}_{3}\left(\mathrm{Si}_{2} \mathrm{O}_{5}\right)(\mathrm{OH})_{4}\right)$ and talc $\left(\mathrm{Mg}_{3}\left(\mathrm{Si}_{4} \mathrm{O}_{10}\right)(\mathrm{OH})_{2}\right)$ are phyllosilicates [i.e., sheet silicates in which $\left(\mathrm{SiO}_{4}\right)$ tetrahedrons form two-dimensional sheets] with even lower dissolution rates. Tectosilicates [i.e., $\left(\mathrm{SiO}_{4}\right)$ tetrahedrons in a three-dimensional framework structure], such as quartz and feldspar, are among the minerals with the lowest dissolution rates. The connectivity of $\left[\mathrm{SiO}_{4}\right]$ tetrahedrons increases from nesosilicate, sorosilicate, inosilicate, and phyllosilicate to tectosilicate with the crystal structures characterized by $\mathrm{Q}^{0}, \mathrm{Q}^{1}, \mathrm{Q}^{2}, \mathrm{Q}^{3}$, and $\mathrm{Q}^{4}$ units, respectively [33]. The notation $\mathrm{Q}^{n}(n=0-4)$ refers to the connectivity of the $\left[\mathrm{SiO}_{4}\right]$ unit in silicate, and $n$ represents the number of $\mathrm{SiO}_{4}$ units connected to a given silicon atom through the shared oxygen (bridging oxygen). The increased connectivity limits the pathways for the $\left[\mathrm{SiO}_{4}\right]$ units to detach from the network structure and decreases the dissolution rate.

For noncrystalline solids such as glass, following the same concept for silicate tetrahedral connectivity, a topological constraint theory was developed to understand the chemical durability and other properties of the materials [34, 35, 36, 37]. Used as a quantitative description of the structure (structural descriptor), the topological constraint per atom $\left(n_{\mathrm{c}}\right)$ is defined as follows:

$$
n_{\mathrm{c}}=\langle r\rangle / 2+(2\langle r\rangle-3),
$$

where $\langle r\rangle$ is the average coordination number. The first term describes the rigid bond constraints, and the second term describes the angular constraints [36]. Although the theory was developed to understand the rigidity of the structure and the physical properties of glasses, the theory has also been used to understand the dissolution kinetics of glasses. As $n_{\mathrm{c}}$ increases, the activation energy of the dissolution reaction increases linearly for a number of silicate crystalline phases and glasses

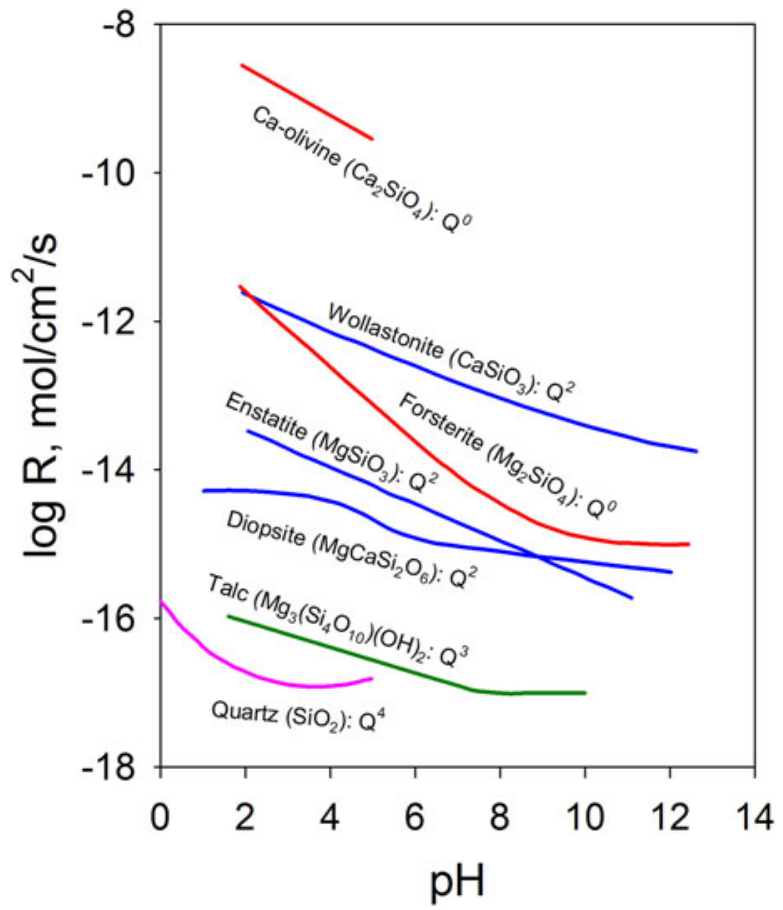

Figure 1: Dissolution rate of $\mathrm{Ca} / \mathrm{Mg}$ silicates at $25^{\circ} \mathrm{C}$ as a function of $\mathrm{pH}$ (enstatite at $70{ }^{\circ} \mathrm{C}$ ) and the connectivity of $\left[\mathrm{SiO}_{4}\right]$ tetrahedrons. Data are from Ref. 10 and the references therein. The rate is the forward rate.

[38, 39]. The number of constraints describes the structural connectiveness and serves as an effective activation energy indicator, which arises from steric effects that prevent the network from reorganizing locally to form an activated surface complex that detaches during dissolution.

The metal-oxygen bond strength, a derived property from the composition, can be related to the bond dissociation in oxides. The parameter has been used to understand the surface reactions of oxides [40,41, 42, 43, 44, 45]. As the bond strength increases, the solubility and dissolution rate decrease [44]. Different from the concept of metal-oxygen bond strength and also less quantitative, the bond valence method (not to be mistaken for the valence bond theory in quantum chemistry) was developed, which is based on Pauling's coordination chemistry rules. The method was originally used in coordination chemistry for validating a proposed chemical structure and the oxidation states of atoms but can be used to understand the properties of a given structure. The bond valence rule stipulates that the valence $V$ of an atom equals the sum of the individual bond valence $v_{i}$ surrounding the atom: $V=\sum v_{i}$, and $v_{i}=$ $\exp \left(\left(R_{\mathrm{o}}-R_{\mathrm{i}}\right) / b\right)$, where $R_{\mathrm{i}}$ is the observed bond length, $R_{\mathrm{o}}$ is the ideal bond length when the element $i$ has an exact valence of 1 , and $b$ is an empirical constant, typically $0.37 \AA$ [46]. A deviation of the bond valence sum from the atomic valence needs to be accounted for, and such a deviation is often associated with bond length and coordination distortion. Bond 
valence method has been applied for predicting the bonding geometry (e.g., bond length and coordination number) and oxidation state of atoms of crystals and the surfaces of oxides, which can be used to understand the surface reactivity and dissolution mechanism of oxides in aqueous solutions. As the bond valence sum deviates from the valence, the stability of the structure decreases, and the solubility and dissolution rate increase. The bond valence method is simple to use for constructing plausible structures, given only the composition. However, it is restricted to compounds with localized bonds. It does not, in general, apply to metals and compounds where the electrons are delocalized.

Quite often, bond strength and structural features are combined to formulate a structural descriptor to describe the structure and composition. For instance, fnet, which combines local structure characteristics and single bond strength, is defined as,

$$
F_{\text {net }}=1 / N \sum_{\mathrm{X}}^{\text {cations }} n_{x} \cdot \mathrm{CN}_{\mathrm{XO}} \cdot \mathrm{SBS}_{\mathrm{XO}} \cdot m_{\mathrm{X}}
$$

where $N$ is the total number of atoms, $n_{x}$ is the number of atoms of the $X$ species, $\mathrm{CN}_{\mathrm{XO}}$ is the average coordination number of $\mathrm{X}-\mathrm{O}$ pairs, $\mathrm{SBS}_{\mathrm{XO}}$ is the single-bond strength or energy $(\mathrm{kcal} / \mathrm{mol})$ [47], and $m_{\mathrm{X}}$ is a factor to account for the contribution of each cation to the overall network strength [48]. Fnet can be used to quantitatively understand the structure-property relationships of glass materials, including the overall strength of the glass network and the dissolution of borosilicate glasses [48, 49].

Defects in oxides are structural and compositional features and have a strong impact on their chemical durability. Structural and compositional defects in crystalline materials are well defined and have been studied extensively [50]. For glassy materials, because of the lack of long-range order [51], the concept of defects for glasses cannot be simply defined in the same way as for crystalline materials. To apply the concept of point, linear, and planar defects of crystals, glassy materials present 3-dimensional long-range defects that extend throughout the material. Such a lack of long-range order may be quantified by the degree of disorder, but distinctions between what would be considered a regular structural character in glasses and a genuine defect in crystals may not exist. Nonetheless, at short and intermediate ranges, order does exist in glasses $[52,53]$. Some defect types in glasses at the range where order does occur are expected to be similarly defined as in crystals, but it is challenging to quantify them. As a result, the effects of defects on the properties of oxides are mostly only applied to materials with long-range order in at least one dimension. Structural defects such as dislocations in crystalline materials are common defects that occur during formation or synthesis processes and can also arise from radiation damage or stress. Defects of any kind increase the enthalpy of formation of a material. The entropic contribution of defects to the total free energy is often relatively low for simple oxides at low temperatures. As a result, defects increase the free energy of formation, which in turn increases the solubility of the material. Compared with a material of the same composition without defects, the solubility of a material with defects increases by a factor of $e^{\Delta G_{\mathrm{f}}^{\mathrm{d}} / R T}$, where $\Delta G_{\mathrm{f}}^{\mathrm{d}}, R$, and $T$ are the excess free energy (i.e., free-energy difference between the material with and without defects), gas constant, and temperature, respectively. The dissolution rate can also increase because of the reduced activation barrier for dissolution as a result of the increased number of defects in the materials, which has been demonstrated in a number of experiments $[54,55,56,57,58,59,60$, $61,62]$. Defects induced by irradiation in materials have similar effects on the solubility and dissolution kinetics $[63,64,65,66]$. However, initial enhancement in dissolution may diminish as the defects induced by irradiation are exhausted if the damage mostly occurs near the surface region [63]. When the dominant process in a dissolution is controlled by defects, unique dissolution mechanisms associated with the type of defect may develop, and the resulting dissolution kinetics can be significantly deviated from the dissolution kinetics of materials without defects. This is because the energetics of the dissolution reaction at the defect sites are modified by the defects. For instance, dislocation defects are common linear defects in crystals that induce a strain energy in crystals and often cause etch pit formation. Dissolution rates of materials with dislocation defects have been explained by a stepwave dissolution mechanism, and the rate becomes nonlinear as the dissolution condition approaches equilibrium conditions (more discussion in section "Dissolution rate as the solution approaches saturation") [56]. Grain and phase boundaries in ceramics and rocks are another source of defects and become important in dissolutions as the grain size decreases below the submicrometer scale. The excess free energy from the interfacial energy is expected to enhance the grain boundary dissolution as a number of experiments have suggested $[67,68,69,70]$. Dissolution at the boundaries may penetrate to a great depth assisted by the enhanced dissolution kinetics if the transport of reactive species within gain boundaries is not the rate-determining step. Because of the finite thickness of grain boundaries, dissolution at the boundaries may be time dependent as the reactive boundaries may be exhausted over time.

\section{Linear free-energy relationships between different types of reactions}

Chemical reactions of different kinds involving the same species are intimately connected by the intrinsic properties of the species. This is evident for many types of reactions, 
including solvation, substitution, ligand exchange, adsorption, and dissolution reactions. Linear free-energy relationships (LFERs) have been established with attempts to develop quantitative relationships between the structure and reactivity for different types of aqueous and mixed-solvent organic reactions. In addition, reaction rates and equilibrium constants are related for a group of closely related reactions [71, 72, 73]. One of these relationships is the Hammett equation, which was developed to predict the equilibrium constant or reaction rate constant of a substitution reaction in solution:

$$
\log \frac{K}{K_{\mathrm{o}}}=\sigma \cdot \rho
$$

where $K_{\mathrm{o}}\left(\right.$ or $\left.k_{\mathrm{o}}\right)$ and $K($ or $k$ ) are equilibrium constants (or reaction rate constant) for the reference and substituted reactions, respectively [72]. The $\sigma$ and $\rho$ are characteristic constants related to the substitute and type of reaction, respectively. Similarly, the rate constant $k_{1}$ of one series of reactions (e.g., water exchange) is related to the rate constant $k_{2}$ of another similar series (e.g., adsorption or dissolution) by:

$$
\log k_{1}=a \cdot \log k_{2}+b,
$$

where $a$ and $b$ are constants. Establishing free-energy relationships helps in understanding the reaction mechanism for a chemical reaction and allows for prediction of the reaction rates and equilibrium constants for less well-known and closely related reactions from well-studied reference reactions. This is especially valuable because complex reactions such as dissolutions involving interfacial reactions are challenging to investigate and probe directly, whereas some related simple reactions may already be well documented.

For instance, the water-exchange reaction, that is, the exchange of a water molecule bound to an ion with another water molecule in bulk solution, is a simple reaction involving ions in an aqueous solution. The reaction kinetics have been well documented for a variety of aqueous ions in the literature $[74,75,76,77,78]$. As shown in Fig. 2, the water-exchange rate varies by over 20 orders of magnitude from very fast exchange (e.g., $\sim$ one exchange in 10 ps for $\mathrm{I}^{-}$) to very slow (e.g., $\sim$ one exchange in over 200 years for $\mathrm{Ir}^{3+}$ ). Based on the linear freeenergy relationship, the rates of dissolution reactions of oxides and adsorption reactions should be linearly correlated to the rate of the closely related reactions-water-exchange reaction. Indeed, oxides consisting of ions with fast water-exchange rates, such as alkali and alkaline earth oxides, and some transition metal and rare earth oxides have higher dissolution rates than oxides with low water-exchange rates. Experimental observations have demonstrated a linear relationship between the metal cation adsorption reaction on a substrate and the waterexchange reaction [Fig. 3(a)] and between the dissolution reaction and the water-exchange reaction [Fig. 3(b)] [79, 80, 81, 82]. By

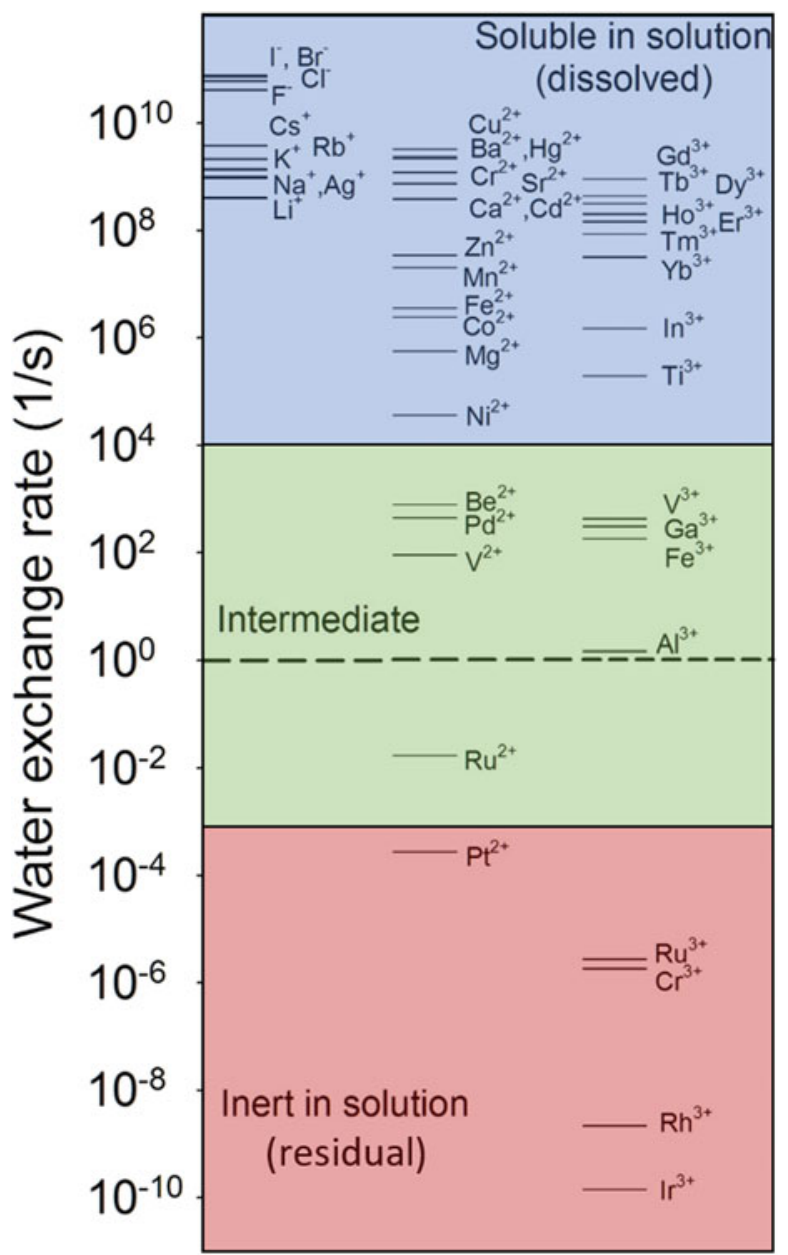

Figure 2: Water-exchange rate constant for a particular water molecule in

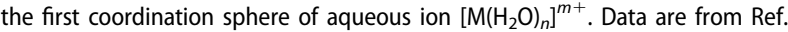
78. The dashed line refers to the exchange rate of $1 \mathrm{~s}^{-1}$.

extending the relationship to all aqueous ions, they (Fig. 2) can be grouped into three categories: mobile ions with fast water exchange $\left(k_{\mathrm{H}_{2} \mathrm{O}}>10^{+4} \mathrm{~s}^{-1}\right)$, intermediate $\left(10^{+4} \mathrm{~s}^{-1} \geq k_{\mathrm{H}_{2} \mathrm{O}}\right.$ $\left.>10^{-3} \mathrm{~s}^{-1}\right)$, and inert ions with slow water exchange $\left(k_{\mathrm{H}_{2} \mathrm{O}} \leq\right.$ $\left.10^{-3} \mathrm{~s}^{-1}\right)$. The corresponding oxides can then be regarded as soluble, intermediate, and insoluble (inert) in water. For multiple cation oxides, the insoluble components may become residuals after soluble components are dissolved in solution.

The water-exchange rate of an aqueous ion is mainly controlled by the strength of the interactions between the ion and water. A linear correlation was established between the water-exchange rate and the ionic potential for a number of aqueous ions [28]. If such a linear correlation can be extended to a broad range of aqueous ions, the ionic potential can then be used to predict the dissolution rates of the oxides of these ions. Figure 4 plots the water-exchange rate as a function of ionic potential for all the aqueous ions in Fig. 2. The data fall into two groups: the cations following a straight line with a slope similar to that previously proposed for a number of 

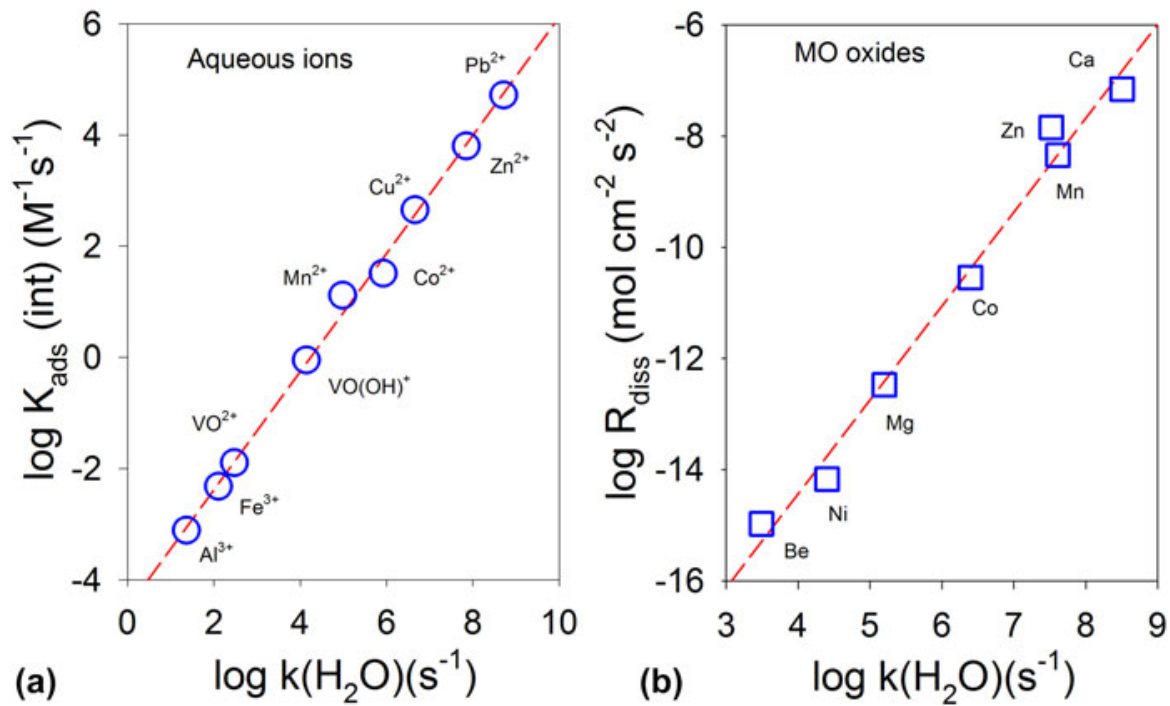

Figure 3: Rate of metal cation adsorption on $\gamma-\mathrm{Al}_{2} \mathrm{O}_{3}$ (a), and the rate of dissolution at $25^{\circ} \mathrm{C}$ and $\mathrm{pH}=2$ of metal oxide $\mathrm{MO}$ having a rock-salt structure (b) as a function of the rate constant of water exchange of the corresponding metal cation in solution. Data for (a) and (b) are from Refs. 79 and 80 , respectively.

divalent and trivalent cations [28] and those cations following a steeper line. If the linear relationship for the first group remains, projections can be made for a broad range of cations, including hypothetical aqueous ions in the form of $\left[\mathrm{M}\left(\mathrm{H}_{2} \mathrm{O}\right)\right.$ $\left.{ }_{n}\right]^{z+}$ with high $z$ values. As shown in Fig. 4, the water-exchange rates of $\mathrm{Ti}^{4+}, \mathrm{Zr}^{4+}$, and $\mathrm{Si}^{4+}$ aqueous ions with coordination numbers of IV and VI are predicted to be orders of magnitude lower than those of alkali, alkaline earth, and rare earth cations. The predicted result is consistent with the very low solubility and dissolution rates of $\mathrm{Ti}^{4+}, \mathrm{Zr}^{4+}$, and $\mathrm{Si}^{4+}$ oxides. The aqueous ions in the second group are open-shell transition metal cations. In addition to the ionic interaction between the ion and water, a strong ligand-field interaction is expected between the electron $d$ orbitals and the water molecule [83, 84], which slows down the exchange reaction and leads to a different relationship with the ionic potential [75].

\section{Dissolution kinetics from thermodynamic equilibrium properties}

Thermodynamic equilibrium properties, such as the solubility of oxides and the formation free energies of oxides and dissolved aqueous species, are well documented in the literature. If a direct relation between the dissolution kinetics and thermodynamic properties can be made, the kinetics can then be predicted based on the equilibrium properties. However, dissolution reactions are often a complex process involving a number of parallel and sequential elementary reactions overall. Based on the formulation that combines the transition state theory (TST) and surface complexation model (SCM) (more discussion in section "TST and SCM"), the surface reaction involving the activated complex is rate limiting. Because, under a given thermodynamic

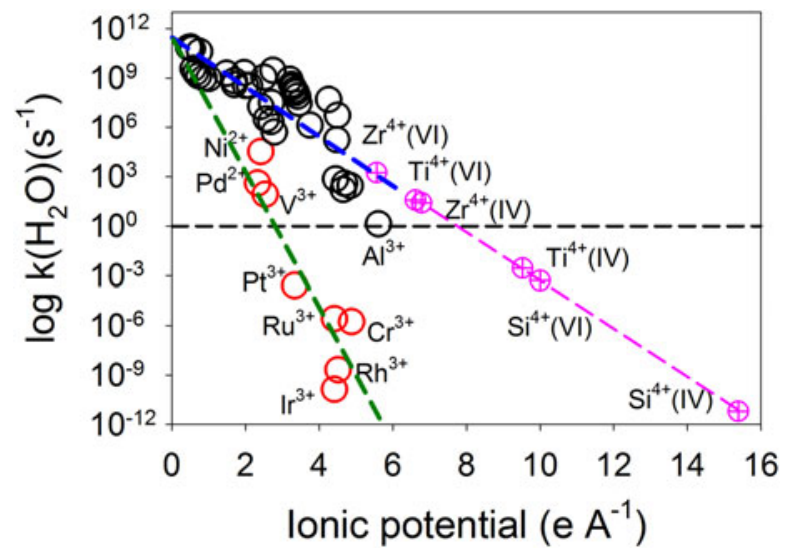

Figure 4: Water-exchange rate constant of aqueous ions as a function of ionic potential. Circles are data from observations, and crossed circles are projected from the linear regression. The roman numbers in parentheses are the coordination number. Dashed thick lines are regression lines. The dashed horizontal line refers to the water exchange rate of $1 / \mathrm{s}$.

condition, the dissolution kinetics of an oxide are defined only by the structure and composition; thus, a link between the dissolution rate and the thermodynamic properties of oxides and their dissolved species is expected to exist.

For a group of materials with the same crystal structure, a linear free-energy relationship has been established, which relates the dissolution rate with the properties of bulk materials and the thermodynamic equilibrium properties of the dissolved aqueous ions $[85,86]$. For a crystalline phase with the chemical formula of $\mathrm{M}_{2} \mathrm{X}, \mathrm{M}$ refers to the substitutive cation and $\mathrm{X}$ is fixed and represents the rest of the structure. The substitution at the crystallographic site $\mathrm{M}$ changes the thermodynamic properties of the phase. For instance, for $\mathrm{M}_{2} \mathrm{SiO}_{4}$ with an olivine structure, $\left[\mathrm{SiO}_{4}\right]=\mathrm{X}, \mathrm{M}$ can be substituted by divalent 
cations such as $\mathrm{Mg}^{2+}, \mathrm{Ca}^{2+}$, and $\mathrm{Ni}^{2+}$. For such a system, a linear free-energy relationship was derived to correlate the free energy of the oxide formation and the properties of the dissolved species [85]. The relationship has been applied to a number of other oxides $[87,88,89,90]$. Furthermore, the free energy of formation of the surface-activated complex $\left(\Delta G_{\mathrm{f}}^{\#}\right)$ is related to the radius-corrected Gibbs free energy of formation $\left(\Delta G_{\mathrm{f}^{\prime}, \mathrm{M}^{2+}}^{\mathrm{o}}\right)$ of an aqueous $\mathrm{M}^{2+}$ cation and the ionic radius $\left(r_{\mathrm{M}^{2+}}\right)$ of the $\mathrm{M}^{2+}$ cation [86]:

$$
\Delta G_{\mathrm{f}}^{\#}=a^{\#} \cdot \Delta G_{\mathrm{f}^{\prime}, \mathrm{M}^{2+}}^{\mathrm{o}}+b^{\#}+\beta^{\#} \cdot r_{\mathrm{M}^{2+}},
$$

where $\Delta G_{\mathrm{f}^{\prime}, \mathrm{M}^{2+}}^{\mathrm{o}}=\Delta G_{\mathrm{f}, \mathrm{M}^{2+}}^{\mathrm{o}}-\Delta G_{\mathrm{s}, \mathrm{M}^{2+}}^{\mathrm{o}}$, and $a^{\#}, b^{\#}$, and $\beta^{\#}$ are constants, $\Delta G_{\mathrm{f}, \mathrm{M}^{2+}}^{\mathrm{o}}$ is the Gibbs free energy of formation of aqueous $\mathrm{M}^{2+}$, and $\Delta G_{\mathrm{s}, \mathrm{M}^{2+}}^{\mathrm{o}}$ is the free energy of solvation of aqueous $\mathrm{M}^{2+}$. By linking the free energy of formation of the surface-activated complex $\left(\Delta G_{\mathrm{f}}^{\#}\right)$ to the dissolution rate $(r)$, $\Delta G_{\mathrm{f}}^{\#}=\Delta G_{\mathrm{r}}^{\#}+\Delta G_{\mathrm{f}}^{\mathrm{o}}+n \Delta G_{\mathrm{f}, \mathrm{H}^{+}}^{\mathrm{o}}$ and $\Delta G_{\mathrm{r}}^{\#}=-R T \ln (r)$, a linear free-energy relationship was derived:

$$
R T \ln (r)=a \cdot \Delta G_{\mathrm{f}^{\prime}, \mathrm{M}^{2+}}^{\mathrm{o}}+b+\beta \cdot r_{\mathrm{M}^{2+}},
$$

The is the empirical effective free energy of reaction forming a surface complex, is the free energy of the formation of $\mathrm{M}_{2} \mathrm{X}$, is a constant, and is apparent free energy of formation of hydrogen ion. It is assumed that the formation of the surface complex involves only the addition of $\mathrm{H}^{+}$ions to the surface of the solid. There, the dissolution rate is related to the ionic radius of the substitution cation and the free energy of formation, and solvation of the cation. As shown in Fig. 5, the linear free-energy relationship [Eq. (5)] is demonstrated for $\mathrm{MO}$ with a rock salt structure and $\mathrm{M}_{2} \mathrm{SiO}_{4}$ with an olivine structure, where $\mathrm{M}$ represents divalent cations [86].

The above examples demonstrate that the linear freeenergy relationship is able to relate the dissolution reaction rate of an oxide to the thermodynamic equilibrium properties of the constituent cations in the crystal and solution. However, caution should be taken for the generalization of the relationship between the kinetics and thermodynamic equilibrium properties because of the lack of a sound thermodynamic basis. In general, the exact linearity between the logarithm of the rate and the equilibrium properties in many favorable cases can be considered "as the first-order approximation of a complicated function" [91]. Such a function may involve details of the crystal structural features that control surface reactions and the surface-activated complex at the interface with the aqueous solution. One example of such attempts is a recent study of the $\mathrm{pH}$ dependence of the dissolution rate of feldspar on the stoichiometry of feldspar, which used the details of the feldspar crystal structure, such as the connection schemes of the tetrahedral framework and ordering of $\mathrm{Al}$ and $\mathrm{Si}$ at the tetrahedral sites [92, 93]. If such an approach is applied to different groups of minerals and ceramics, formulations will have to be customized to account for the details of the structure and composition of the individual phases.

\section{TST and SCM}

The current formulation of oxide dissolution kinetics in aqueous solutions is based on the TST and the SCM [10, 15, $94,95]$. The basic idea behind the TST is that, for elementary chemical reactions, there is a quasi-equilibrium between the reactants and the activated complexes, and the statistical kinetic theory can be used to calculate the conversion rate from the activated complexes (the transition state) to the products, which are at the saddle point of the potential energy surface. For a simple reaction in the gas phase, the reaction takes place when molecules collide with enough energy to traverse the energy barrier of the energy surface. For dissolution reactions at surfaces, the TST has been employed to describe the ratelimiting elementary reaction associated with the surface-activated complex (the transition state) $[4,8]$. The bulk material and dissolved species in the solution are not explicitly presented in the surface-activated complex. Instead, the SCM is used to describe the equilibrium between the surface speciation and solution chemistry $[96,97]$. By combining the TST and SCM, the TST-SCM formulation stipulates that there is equilibrium for surface reactions involving the adsorption of dissolved aqueous species from the solution and the ion exchange between the surface and solution, and these reactions lead to surface complexes. The rates of these reactions are relatively fast and are not the rate-determining steps of the overall dissolution reaction. The surface complexes serve as reactive surface precursors that may transform into the surfaceactivated complex, which is considered the transition state for the detachment of dissolving species. Such a formulation connects two elementary reactions, that is, surface adsorption and detachment, by the concept of a surface complex and reactive precursor. The reactive surface precursors are assumed to be stoichiometrically identical to and will proportionally transform into the surface-activated complex, a transition state in the rate-limiting reaction of the dissolution process $[98,99]$. Therefore, the overall dissolution reaction rate is proportional to the concentration of the surface precursors, which can be quantified using a SCM and solution chemistry. The dissolution rate can then be simplified by identifying the surface reaction that leads to the activated complex and by formulating a rate equation as a function of the activities of different aqueous species in the solution.

The dissolution of single-oxide minerals is the best example to illustrate the effectiveness of the TST-SCM formulation in 

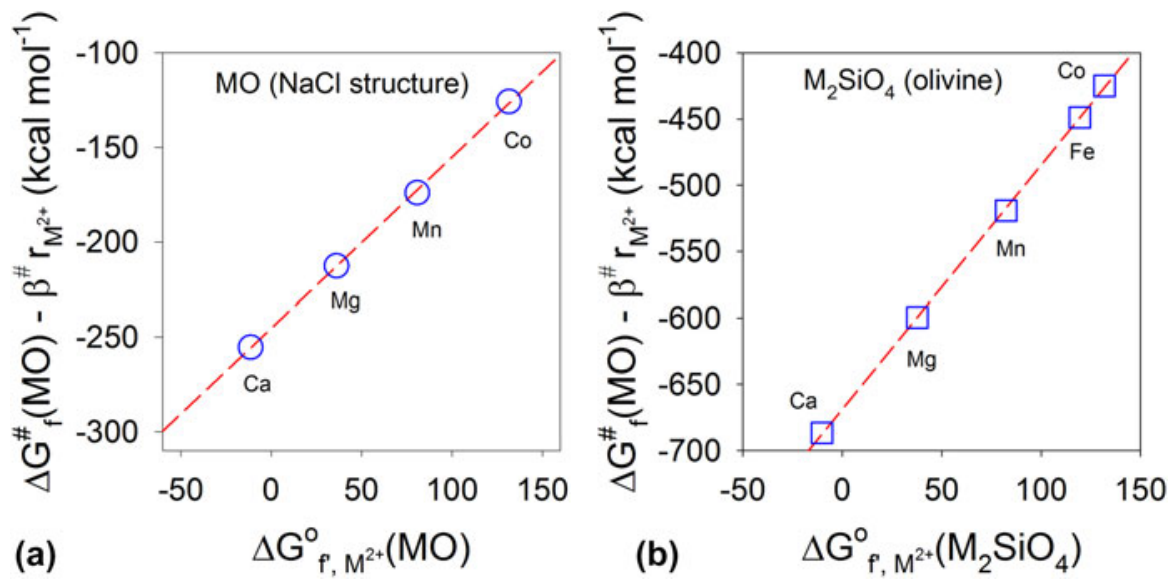

Figure 5: A graphic representation of Eq. (5) rearranged to $\Delta G_{f}^{\#}-\beta^{\#} \cdot r_{\mathrm{M}^{2+}}=a^{\#} \cdot \Delta G_{f^{\prime}, \mathrm{M}^{2+}}^{\mathrm{O}}+b^{\#}$. Effective free energy for the formation of surface complexes on metal oxides with rock salt structures (a) and orthosilicates with olivine structures (b). The symbols are calculated from experimental data. The dashed lines are regression lines. Adapted from Ref. 86.

describing the dissolution kinetics [15, 94]. The dissolution rate can be described from the sum of the parallel reactions occurring at metal centers with different surface species [10]:

$$
r_{+}=\sum_{\mathrm{L}} k_{\mathrm{L}}[>\mathrm{ML}]^{n_{\mathrm{L}}}+k_{\mathrm{H}_{2} \mathrm{O}}
$$

where $>$ refers to the surface, $[>\mathrm{ML}]$ is the surface complex concentration, $\mathrm{L}=\mathrm{O}, \mathrm{OH}, \mathrm{OH}_{2}$, or other species, and $n_{\mathrm{L}}$ is the reaction order of the surface species-promoted dissolution, $k_{\mathrm{L}}$ is the rate constant for the corresponding surface complex, and the second term $k_{\mathrm{H}_{2} \mathrm{O}}$ is the water-promoted dissolution, which becomes dominant when $[>\mathrm{ML}]$ is very low, for instance, at a $\mathrm{pH}$ near the surface isoelectric point. The reaction order term, $n_{\mathrm{L}}$, can be determined experimentally. The dissolution of brucite $\left(\mathrm{Mg}(\mathrm{OH})_{2}\right)$ demonstrates the application of the equation Eq. (5) [100]. The bulk truncated surface of brucite is terminated by $>\mathrm{Mg}-\mathrm{OH}^{0}$, and surface reactions lead to additional surface

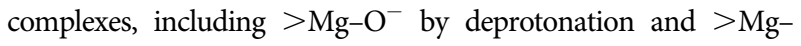
$\mathrm{OH}_{2}{ }^{+}$by protonation. The rate-limiting step of the dissolution is the bond breaking of $\mathrm{Mg}-\mathrm{O}$, which is enhanced by forming a $>\mathrm{MgOH}_{2}{ }^{+}$surface complex because the additional proton weakens the $\mathrm{Mg}-\mathrm{O}$ bond. For parallel reactions, the fastest reaction controls the overall rate. Thus, the dissolution equation is then simplified to

$$
r_{+}=k_{\mathrm{MgOH}_{2}^{+}}\left[>\mathrm{MgOH}_{2}^{+}\right]^{2} .
$$

The exponent originates from the fact that it requires two $>\mathrm{MgOH}_{2}^{+}$surface species to form the surface-activated complex to break an $\mathrm{Mg}-\mathrm{O}$ bond [101, 102, 103]. An inspection of brucite crystal structure suggests this interpretation of the reaction mechanism is reasonable. In bulk brucite structure, each $\mathrm{Mg}$ is coordinated to $6 \mathrm{OH}$ groups in an octahedral coordination, these octahedrons share edges, and each $\mathrm{OH}$ group is bonded to 3 $\mathrm{Mg}$. At the surfaces [104], if one $\mathrm{OH}$ is doubly protonated, a surface complex $>\mathrm{MgOH}_{2}^{+}$will form, which weakens the 3 $\mathrm{Mg}-\mathrm{O}$ bonds equally. Another doubly protonated $\mathrm{OH}$ group at a neighboring position would further weaken one of the $3 \mathrm{Mg}-\mathrm{O}$ bonds and break it. As shown in Fig. 6, the concentration of the surface complex $>\mathrm{MgOH}_{2}{ }^{+}$decreases [Fig. 6(a)] with $\mathrm{pH}$, as does the dissolution rate [Fig. 6(b)]. Other surface complexes,

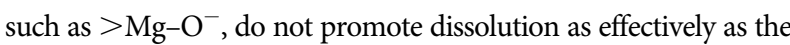
$>\mathrm{MgOH}_{2}{ }^{+}$complex. Similar formulations have been used to explain the dissolution rates of simple oxides, such as quartz [105, $106,107]$, boehmite and gibbsite [94, 108, 109], $\mathrm{BeO}, \delta-\mathrm{Al}_{2} \mathrm{O}_{3}$, and ferric oxides [15, 94].

Equation (7) can also be used to explain the dissolution kinetics of carbonates $\left(\mathrm{MCO}_{3}, \mathrm{M}=\right.$ divalent metal cation). The surfaces of carbonate minerals in solution are characterized by metal cations and carbonate units interacting with water. Adsorption of protons at carbonate units at acidic $\mathrm{pH}$ values and adsorption of water molecules at the metal cations at neutral to basic $\mathrm{pH}$ values weaken the $\mathrm{M}-\mathrm{CO}_{3}$ bonds, form surface-activated complexes (i.e., $>\mathrm{CO}_{3} \mathrm{H}$ and $>\mathrm{MOH}_{2}$ ), and promote dissolution $[110,111]$. The rate equation for these two surface complexes is

$$
r_{+}=k_{\mathrm{H}}\left[>\mathrm{CO}_{3} \mathrm{H}\right]^{n_{\mathrm{H}}}+k_{\mathrm{H}_{2} \mathrm{O}}\left[>\mathrm{MOH}_{2}\right]^{n_{\mathrm{H}_{2} \mathrm{O}}},
$$

where $k_{\mathrm{H}}$ and $k_{\mathrm{H}_{2} \mathrm{O}}$ are the rate constants, and $n_{\mathrm{H}}$ and $n_{\mathrm{H}_{2} \mathrm{O}}$ are the reaction order with respect to the protonated carbonate surface complex and water-metal cation complex, respectively. For magnesite $\left(\mathrm{MgCO}_{3}\right)$, the orders of $n_{\mathrm{H}}$ and $n_{\mathrm{H}_{2} \mathrm{O}}$ are 4 , as shown in Fig. 7 [112]. For calcite $\left(\mathrm{CaCO}_{3}\right)$, the orders are 2 and 1 for $n_{\mathrm{H}}$ and $n_{\mathrm{H}_{2} \mathrm{O}}$, respectively [81]. For dolomite $\left(\mathrm{CaMg}\left(\mathrm{CO}_{3}\right)\right.$ ${ }_{2}$ ), the orders of $n_{\mathrm{H}}$ and $n_{\mathrm{H}_{2} \mathrm{O}}$ are $2[81,113]$. The $n_{\mathrm{H}}$ and $n_{\mathrm{H}_{2} \mathrm{O}}$ values depend on the strength of the $\mathrm{M}-\mathrm{O}$ bond, and a strong bond leads to a higher order [81]. The higher reaction orders suggest that breaking a bond between $\mathrm{Ca}^{2+}$ and $\mathrm{CO}_{3}{ }^{2-}$ requires more than one surface complex working in a concerted manner to promote dissolution. 

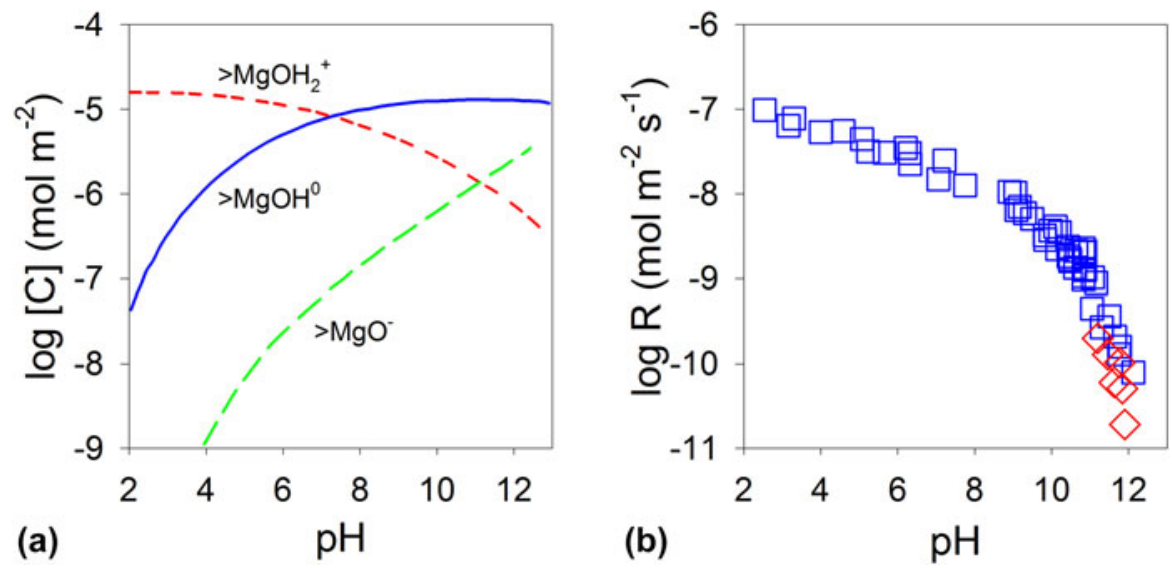

Figure 6: Brucite $\left(\mathrm{Mg}(\mathrm{OH})_{2}\right.$ surface speciation (a) and dissolution rate at $20{ }^{\circ} \mathrm{C}$ (b) as a function of solution pH. The surface speciation is based on a constant capacitance model with a constant of $5 \mathrm{~F} / \mathrm{m}^{2}, 0.01 \mathrm{~mol} / \mathrm{L} \mathrm{NaCl}$ solution, and using a $2 \mathrm{pK} \mathrm{SCM}$. Diamond symbols (red) in (b) are rates measured close to equilibrium. Adapted from Ref. 100.
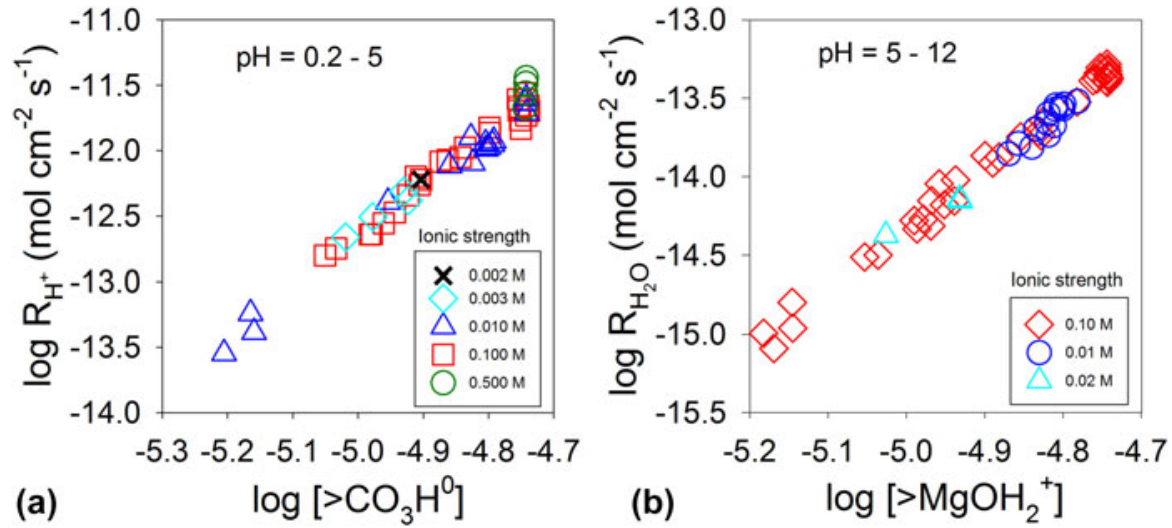

Figure 7: Magnesite $\left(\mathrm{MgCO}_{3}\right)$ dissolution rate at $25^{\circ} \mathrm{C}$ as a function of $>\mathrm{CO}_{3} \mathrm{H}^{0}$ (a) and $>\mathrm{MgOH}_{2}{ }^{+}$(b) concentrations at the surface. Adapted from Ref. 112 .

For mixed-cation oxides, the rate-limiting steps are often not simply protonation or deprotonation of surface metal cations because the reactivity of each of the multiple cation sites may differ significantly. Because the leaching of highly reactive cations such as alkali, alkaline earth or other cations by ion-exchange with protons leads to protonations of the still-connected $\left[\mathrm{Si} / \mathrm{AlO}_{4}\right]$ tetrahedral network in silicates, the formation of the surface dissolution precursor is controlled by the exchange reaction between metal cations and proton $[10,45,114]$ :

$$
z n \mathrm{H}^{+}+>\mathrm{M}-\mathrm{O}=P^{*}+n \mathrm{M}^{z+},
$$

where $z$ is the metal cation charge and $n$ is the number of cations to be removed to create $P^{\star}$ (surface precursor complex). Using the law of mass action of the reaction and assuming the total surface site is $S$, the forward rate is derived as

$$
r_{+}=k_{\mathrm{P}^{*}}\left[P^{*}\right]=k_{P^{*}} S\left[\frac{K_{\mathrm{eq}}^{P^{*}}\left(a_{\mathrm{H}^{+}}^{z} / a_{\mathrm{M}^{z+}}\right)^{n}}{1+K_{\mathrm{eq}}^{P^{*}}\left(a_{\mathrm{H}^{+}}^{z} / a_{\mathrm{M}^{2+}}\right)^{n}}\right],
$$

where $k_{P^{*}}$ is the forward rate constant, $\left[P^{*}\right]$ is the concentration of the precursor complex, $K_{\mathrm{eq}}^{P^{*}}$ is the equilibrium constant of the surface complexation reaction, and $a_{\mathrm{H}^{+}}$and $a_{\mathrm{M}^{z+}}$ are the activities of the proton and metal cation in the solution. This equation leads to the dissolution rate that varies with the activities of the leached cations in the solution. If $[>\mathrm{M}-\mathrm{O}] \gg$ $\left[P^{\star}\right], K_{\mathrm{eq}}^{P^{*}}\left(a_{\mathrm{H}^{+}}^{z} / a_{\mathrm{M}^{z+}}\right)^{n} \approx 0$, the rate is reduced to

$$
r_{+}=k_{+} K_{\mathrm{eq}}^{P^{*}}\left(a_{\mathrm{H}^{+}}^{z} / a_{\mathrm{M}^{2+}}\right)^{n} .
$$

These formulations have adequately described a number of silicate dissolution kinetics, including albite $\left(\mathrm{NaAlSi}_{3} \mathrm{O}_{8}\right)[10$, $115,116,117,118]$, K-feldspar $\left(\mathrm{KAlSi}_{3} \mathrm{O}_{8}\right)$ [10, 119], kaolinite $\left(\mathrm{Al}_{2} \mathrm{Si}_{2} \mathrm{O}_{5}(\mathrm{OH})_{4}\right)$ [120], labradorite $\left((\mathrm{Ca}, \mathrm{Na})(\mathrm{Al}, \mathrm{Si})_{4} \mathrm{O}_{8}\right)$ [121], muscovite $\left(\mathrm{KAl}_{2}\left(\mathrm{AlSi}_{3} \mathrm{O}_{10}\right)(\mathrm{OH})_{2}\right)$ [122], basaltic, and other natural glasses $[123,124]$. For example, the dissolution rates of albite, K-feldspar, and kaolinite are accurately described by Eq. (12), where $\mathrm{M}^{z+}=\mathrm{Al}^{3+}$ and $n=0.33$ for albite and K-feldspar [Fig. 8(a)] and $n=1.0$ for kaolinite [Fig. 8(b)]. However, for nesosilicate silicates with individual $\left[\mathrm{SiO}_{4}\right]$ tetrahedra unconnected after completely leaching cations such as $\mathrm{Ca}$ and $\mathrm{Al}$ (anorthite, $\mathrm{CaAl}_{2} \mathrm{Si}_{2} \mathrm{O}_{8}$ ) [45] and $\mathrm{Mg}$ (forsterite, $\mathrm{Mg}_{2} \mathrm{SiO}_{4}$ ) [125], the proton-promoted mechanism [Eq. (7)] still controls 
the dissolution, which is not affected by the concentration of cations leached into solution $[9,10]$. The reaction orders, $n_{\mathrm{L}}$, $n_{\mathrm{H}_{2} \mathrm{O}}$, or $n$, described in Eqs. (7), (9), (11), and (12), are interpreted as the number of surface complexes needed to break a bond, or the number of removed cations to create a surface complex, which are related to the stoichiometry of the surface reactions. In practice, they are often empirically fitted using experimental data. As a result, fractional orders often occur.

\section{Dissolution rate as the solution approaches saturation}

The dissolution rate discussed thus far only focuses on the forward rate of the dissolution reaction, and the reverse reaction rate is not considered. In reality, for a reversible reaction, which is the case for many dissolution reactions, the reverse reaction occurs as soon as the dissolved species are present in the solution. The net reaction rate decreases as the dissolved species accumulate and the rate approaches zero when the solution reaches the solubility limit of the solid. With the assumption of TST and the principle of detailed balance, the dissolution rate as a function of the solution saturation is described by $[4,9,10,126]$ :

$r=k_{+}(1-(Q / K))=k_{+}\left(1-e^{\left(\Delta G_{\mathrm{r}} / R T\right)}\right)=k_{+}\left(1-e^{(-A / R T)}\right)$,

$$
k_{+}=k_{0} \cdot\left[\mathrm{H}^{+}\right]^{\eta} \cdot \prod_{i} a_{i}^{v_{i}} \cdot e^{-E_{\mathrm{a}} / R T},
$$

where $k_{+}, Q, K, \Delta G_{\mathrm{r}}, R, T$, and $A$ are the forward rate, activity product, solubility product, Gibbs free energy of the dissolution reaction, gas constant, temperature, and chemical affinity of the reaction, respectively, and $k_{0},\left[\mathrm{H}^{+}\right], \eta, a_{i}, v_{i}$, and $E_{\mathrm{a}}$ are the forward rate constant, $\mathrm{H}^{+}$activity, reaction order involving $\mathrm{H}^{+}$, activity of aqueous species $i$, reaction order involving species $i$, and activation energy, respectively. Based on the TST-SCM formulation, the surface reaction involving the activated complex is rate limiting. Therefore, the stoichiometry of the overall dissolution reaction may or may not reflect the stoichiometry of the rate-determining reaction that involves the surface-activated complex. The difference between the stoichiometries is factored in Eq. (15) as a constant $\sigma$ (Temkin's average stoichiometric number) to adjust the Gibbs free-energy driving force for the overall reaction.

$$
r=k_{+}\left(1-e^{\left(\Delta G_{\mathrm{r}} / \sigma R T\right)}\right) .
$$

The constant $\sigma$ refers to the relative proportion of destruction of the activated complex with respect to the overall dissolution reaction [45]. Although the underlying assumptions of the equation only consider elementary reversible reactions, the overall dissolution reaction is often limited by the elementary reaction involving the surface-activated complex. Therefore, the equation has been widely applied to a diverse range of dissolution reactions of oxide minerals $[9,10]$. Similar principles and formulations have also been applied to glasses [45, $124,127,128]$.

However, many mineral dissolution behaviors cannot be fit by Eqs. (13) or (15), which are linear in $\Delta G_{\mathrm{r}}$. They have an exponential dependence on $\Delta G_{\mathrm{r}}$ that approaches equilibrium more slowly. Such a modified equation using an empirical approach was often considered useful to describe reactions affected by crystal defects [9].

$$
r=k_{+}\left(1-e^{\left(\Delta G_{\mathrm{r}} / \sigma R T\right)}\right)^{m}
$$

where $m$ is a constant. This equation has been used to describe the dissolution of kaolinite [129], gibbsite $\left(\mathrm{Al}(\mathrm{OH})_{3}\right)$ [130], quartz [131] and other oxide minerals [9]. The physical meaning of the $m$ value, however, is not well understood, and complex surface phenomena must be involved in dissolution kinetics when $m$ deviates from unity $[9,132]$. Cases with $m$ $=1$ and $m \neq 1$ have both been reported in the literature [9], which are considered to be either consistent with $(m=1)$ or not consistent $(m \neq 1)$ with the TST. Nonetheless, the latter has been interpreted to be related to surface defects playing a role in dissolution.

Using a mechanistic approach, a dissolution stepwave model, a generalized model to account for the effect of surface dislocation defects, was developed to account for a deviation from the TST [56]. The model emphasizes a critical free energy $\left(\Delta G_{\text {crit }}\right)$ for opening up etch pits that lead to accelerated dissolution. The model is a modification of the existing rate equation [i.e., Eq. (13)] that includes a factor from the contribution of the defects to the dissolution [56]:

$$
\begin{gathered}
r=k_{+}\left(1-e^{\left(\Delta G_{\mathrm{r}} / R T\right)}\right) \tanh \left[B / f\left(\Delta G_{\mathrm{r}}\right)\right] f\left(\Delta G_{\mathrm{r}}\right), \\
f\left(\Delta G_{\mathrm{r}}\right)=\left(1-\frac{1-e^{\Delta G_{\text {crit }} / R T}}{1-e^{\Delta G_{\mathrm{r}} / R T}}\right),
\end{gathered}
$$

where $B$ is a constant. The rate equation has been used to explain the dissolution behaviors of albite, gibbsite, labradorite, and smectite [56], and, more recently, calcite [133]. For oxide glasses, due to the lack of long-range order [51], similar defects may not exist. Although order does exist in glasses at short and intermediate ranges [52, 53], the formulations described above for the associated defects may not be applicable. 

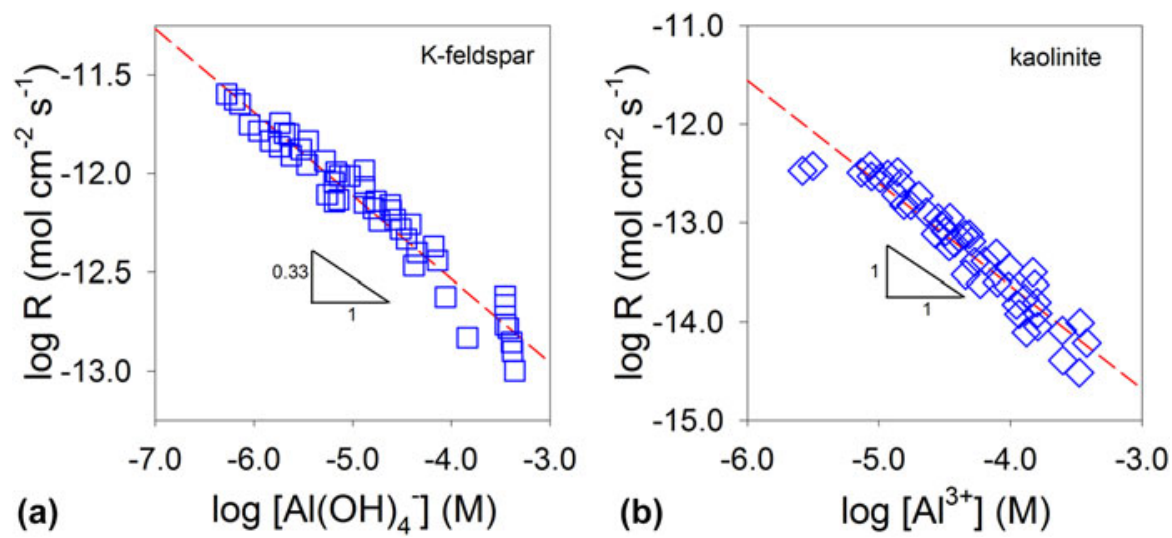

Figure 8: Logarithm dissolution rate of $\mathrm{K}$-feldspar at $150{ }^{\circ} \mathrm{C}$ and $\mathrm{pH}=9$ as a function of $\mathrm{Al}(\mathrm{OH})_{4}{ }^{-}$concentration (a), and kaolinite at $150{ }^{\circ} \mathrm{C}$ and $\mathrm{pH}=2$ as a function of $\mathrm{Al}^{3+}$ concentration (b). Symbols are experimental data. Dashed lines are regression lines. Adapted from Ref. 10.

\section{Implications of thermodynamic theories and challenges for understanding the chemical durability of oxides}

\section{Ionic potential as a guide for nuclear waste development}

The development of nuclear waste forms requires the waste elements to be compatible with the host structure and the resulting waste forms to be chemically durable in the environment. These requirements ensure sufficient loading of the waste elements, durable long-term performance, and safety to the environment. Ionic potential $(z / r)$ is a widely used elemental property $[25,26,27,134,135]$ and can be used to understand the structural compatibility of waste elements with the host structure, such as borosilicate glass, and their chemical durability in aqueous solutions.

As shown in Fig. 9, elements are divided into three regions based on their ionic potential: $<3$ (I), $4-8$ (II), and $>10$ (III) $[27,136]$, and there are also elements in between the regions. Ions in region (I) have the lowest ionic potential and polarizing ability and form highly ionic bonds with oxygen. This group includes alkali, alkaline earth, and other divalent and trivalent large cations. These elements are compatible with borosilicate glass and are network modifiers. Because of their low ionic potential, they are highly soluble in water. As a result, they can be leached by ion exchange under acidic conditions. Halogen ions are also included in Fig. 9 to show their relative reactivity based on their absolute ionic potential. Ions in region (II) have an intermediate polarizing ability. They often form insoluble oxides and hydroxides with a covalent bond to oxygen. When incorporated in borosilicate glass, they are intermediates in the silicate glass structure and cannot be easily leached into solution but often form residuals or precipitates after the soluble ions are dissolved in solution. This group includes a range of divalent, trivalent, tetravalent, and pentavalent cations. Rare earth elements (REEs) are located near the boundary of regions

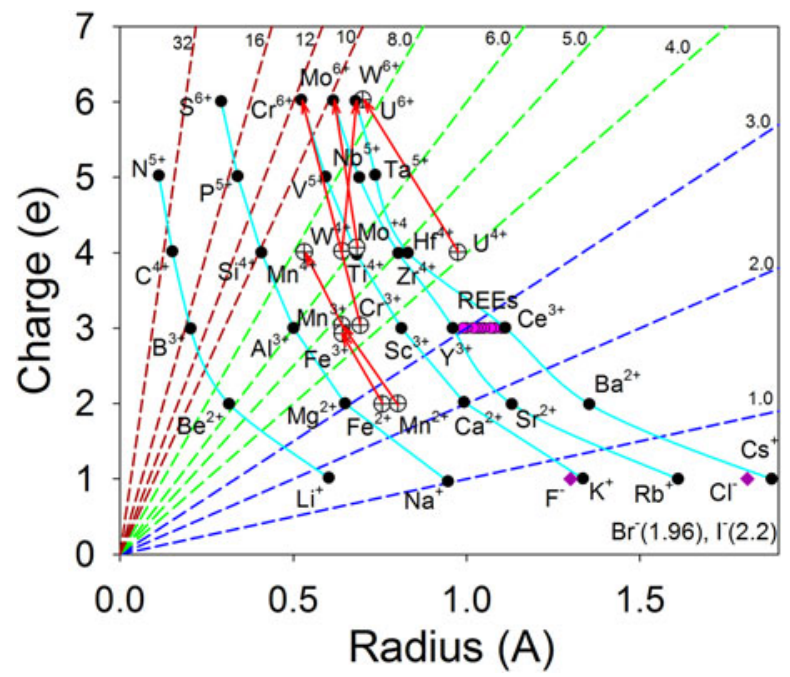

Figure 9: The charge is plotted as a function of ionic radius for a selection of ions. Ionic potential is used to divide the ions into different regions (dashed lines-ionic potential is next to the lines): soluble hydrated ions (I), insoluble oxides and hydroxides (II), and soluble oxyanions (III). Solid cyan lines are eye guides for the ions of the same row in the periodic table. Open crossed circles are redox sensitive ions, and arrows indicate the change property of the ion by oxidation. REEs are pink circles, and Halogen ions are dark red diamonds. Adapted and modified from Refs. 27 and 136.

(I) and (II), suggesting their reactivity is similar to that of the elements in either region. Ions located in region (III) are highly polarizing ions with a high field strength. As a result, they often form an oxyanion rigid unit. Because each of these oxyanions has unique chemistry, they are not necessarily compactible with any host structure, such as borosilicate glass. For instance, the solubility of $\mathrm{Cr}^{6+}, \mathrm{Mo}^{6+}$, and $\mathrm{S}^{6+}$ is low in borosilicate glass. Because of their large size as a rigid oxyanion unit and low nominal charge, these oxyanions are soluble in water. Note that a change in the oxidation state of variable valence elements can move an element from one region to another, which can significantly change the solubility behavior in oxides and solution. For instance, $\mathrm{Cr}^{3+}$ and $\mathrm{Mo}^{4+}$ in region (II) are 
insoluble in aqueous solutions. If oxidized to $\mathrm{Cr}^{6+}$ and $\mathrm{Mo}^{6+}$, they form oxyanions and are in region (III), becoming incompatible with borosilicate glass and insoluble in the glass but soluble in aqueous solutions. The solubility of ferrous iron (region I) in aqueous solution is significantly reduced if oxidized to ferric iron (region II). Based on the ionic potential, nuclear waste elements can then be classified into different groups based on their solubility in the host material and in water. For those with a high solubility in both oxides and aqueous solution, understanding their dissolution behavior is critical for the prediction of their chemical durability in the environment. For those with a high solubility in oxides but with a low solubility in aqueous solution, a high concentration in nuclear waste forms can be achieved without much concern for them being rapidly released into the environment. Problematic waste elements are soluble in water but insoluble in a given waste host material, in which case, special waste forms to target these specific elements are necessary.

\section{Prediction of the dissolution rate of glass and multiphase ceramics using the linear free-energy relationship}

The dissolution rate of single-phase ceramic materials with a given structure can be predicted using a linear free-energy relationship as discussed in the previous section. For aperiodic systems such as glass, however, a direct use of the linear freeenergy relationship for the rate prediction is problematic. Although glass is a single phase, the atomistic scale structure can change significantly with the composition, such as in borosilicate glass [137]. These structural changes need to be considered for rate prediction.

The crystalline reference state (CRS) was proposed to represent the structure and composition of glass materials $[138,139]$ and has been used for modeling the physical properties of borosilicate glass [140, 141]. The fundamental assumption is that the local structure of a glass in the short range is similar to the corresponding crystalline phase of an oxide with a similar composition [142]. At the intermediate range, extensive research shows that the structure of a glass resembles fragments of the structures of the corresponding crystalline phases $[137,143,144,145]$. The similarity in the dissolution mechanisms between silicate minerals and their glasses suggests that dissolution reactions occur at short and intermediate ranges where their structures are similar [146, 147]. For instance, the activation energy for the dissolution of quartz and silica glass is approximately the same [148], suggesting a similar mechanism of breaking the $\mathrm{Si}-\mathrm{O}$ bond in the dissolution of the two phases. Differences in their dissolution rate are related to differences in the distortions of local structure in the glass and different energetics $[149,150]$, which are associated with broader bond lengths and angle distributions, larger molar volumes, and other structural features in glasses that are not present in crystals $[151,152]$. Structural features in oxide glasses such as water-accessible free volume may lead to dissolution mechanisms that are different from those in crystals $[151,152]$. In addition, the stepwave dissolution mechanism that well describes the dissolution kinetics of crystals with dislocation defects may not be applicable to glasses [56]. If the overall dissolution of a glass is simply approximated by the summation of the dissolutions of all CRS phases with parallel dissolution reactions, the linear free-energy relationship could be employed for the prediction of glass dissolutions. The rate becomes a summation of the linear freeenergy relationships of the dissolution [Eq. (6)] for each individual CRS phase and their cross terms.

$$
R T \ln (r)=\sum_{i, j=1, n} f_{i} \cdot \alpha_{i, j} \cdot\left(a_{i} \cdot \Delta G_{\mathrm{f}^{\prime}, \mathrm{M}^{z}}^{\mathrm{o}}+b_{i}+\beta_{i} \cdot r_{i, \mathrm{M}^{2}}\right),
$$

where $i, j$ is a CRS phase, $n$ is the number of CRS phases, $\alpha_{i, j}$ is the effect of phase $j$ on the rate of phase $i$ to account for the coupling effect from cross interactions between different CRS phases, $f_{i}$ is the faction of phase $i$, and $z$ is the charge of the substitution ion. If $i=j$, the coupling constant $\alpha_{i, j}=1$. If $I \neq j$, $\alpha_{i, j} \neq 0$ if the coupling is not ignored, or $\alpha_{i, j}=0$ if the coupling is ignored.

The first step to applying Eq. (19) is to identify the CRS phases that represent the structure and composition of the glass using principles established in the literature $[138,139,140,141$, 153]. For each CRS phase, substitution sites need to be determined, and dissolution rate data need to be characterized for each of the end members. The free-energy relationship of dissolution for each CRS phase will then be established. After all the free-energy relationships for the CRS phases become available, the glass dissolution rate can then be modeled using Eq. (19).

For multiphase ceramic waste forms, the coupling between different phases is reduced to phase boundaries, which can be neglected $\left(\alpha_{i, j}=0, I \neq j\right)$ if the phase boundary density is low.

$$
\ln (r)=\frac{1}{R T} \sum_{i=1} f_{i} \cdot\left(a_{i} \cdot \Delta G_{\mathrm{f}^{\prime}, \mathrm{M}^{z}}^{\mathrm{o}}+b_{i}+\beta_{i} \cdot r_{i, \mathrm{M}^{z}}\right) .
$$

If the grain size is well below the micrometer scale and the phase and grain boundary densities are high, the boundaries cannot be neglected. Both phase and grain boundaries are twodimensional objects with a thickness in the nanometer range and may have a different composition than the corresponding phases. Because they often have higher energies and are more reactive in solution with higher dissolution rates, they should be treated separately from bulk phases. 


\section{Incongruent dissolution and surface alteration layer of multiple-metal oxides}

The dissolution rate formulations described so far assume that the surfaces are free of surface alteration layers or secondary phases. However, observations of many multiple-metal oxides such as aluminosilicate minerals and borosilicate glasses suggest that alteration layers often occur with thicknesses varying from nanometers to micrometers [1]. Such surface layers complicate dissolution kinetics by controlling the transport of reactive species within the layers and influencing the chemistry of the solution. The alteration layer formation originates because each of the elements in multiple-metal oxides has a different chemical bonding character and solubility in solution. The relative rate of breaking the metal-oxygen bonds decreases dramatically from monovalent, divalent, and trivalent to tetravalent ions $[1,10,45]$. This difference leads to incongruent dissolution and the resulting alteration layers at the surface depleted in soluble cations and enriched in insoluble cations. How the alteration layer is formed is currently an area of active research. There are two dominant theories: ion exchange followed by structural reorganization versus stoichiometric dissolution followed by in situ reprecipitation [154, 155, 156]. Both theories have ample experimental and theoretical support $[1,154,155,156,157,158,159,160]$. A major consequence of the different formation mechanisms is that the resulting alteration layers may have different properties and can be amorphous or crystalline, dense or porous [161], and passivating or not. The passivating nature of the alteration layer is caused by slowing down the transport of reacting species through the layer. Therefore, the passivation layer is critical for the applications of nuclear glass and alloys and an important factor in understanding the chemical weathering of minerals in the environment $[1,6,9,10]$.

Dissolution reactions are complex reactions consisting of parallel and sequential elementary reactions involving surface solvation, surface adsorption, ion exchange, hydrolysis, and detachment of surface-activated complexes. These elementary reactions often occur on very different timescales. For instance, surface adsorption reactions are orders of magnitude faster than dissolution reactions (Fig. 3). The relative kinetics of these reactions determine the mechanism of the overall dissolution reaction. If the ion exchange of protons in solution for cations in the oxide solid occurs and the resulting proton-exchanged layer at the surface is stable, the proton-exchanged layer may grow into the material beyond the surface. As the thickness of the hydrated layer increases, instability may develop. For instance, partially proton-exchanged clays and zeolites are stable $[162,163,164]$, but fully proton-exchanged phases are not. Once the stability thickness is surpassed, the hydrated layer will transform into a more stable phase, such as an amorphous layer. In this scenario, the ion exchange followed by the reorganization scheme characterizes the dissolution process well. Because the proton-exchanged layer is two-dimensional, metastable, and temporal, its transformation into an amorphous alteration layer could occur in a layer-by-layer fashion. On the other hand, if the ion exchange causes high instability within the first surface layer and hydrolysis reactions occur immediately, a proton-exchanged layer may be restricted at the very surface and not develop further into the material. In such cases, the alteration layer may become amorphous such as silica gel in silicate dissolutions [157]. In this latter case, dissolution coupled re-precipitation characterizes the process well.

It is most likely that each of the two scenarios highlights one aspect of the spectrum of the dissolution process. It may be constructive to not exclude one theory over the other. Which mechanism dominates the alteration layer formation may largely depend on a number of factors including the composition of the oxide and the solution conditions. However, the alteration layers formed with different mechanisms can have very different properties. The reorganization of the protonexchanged layer may allow some underlying structure of the material to be inherited, while the alteration layer from reprecipitation may only be affected by the local solution chemistry. Thus, stress parallel to the surface may develop in the alteration layer if there is a surface restraint exerted by the underlying structure. Note that not all amorphous alteration layers are passivating, and the passivating properties depend on the formation mechanism, the structure and composition of the material, and the environmental conditions. The exact factors that determine a passivating alteration layer are still elusive. In any case, the altered phase is metastable, either amorphous (e.g., silica gel- $\mathrm{SiO}_{2} \mathrm{nH}_{2} \mathrm{O}$ ) or crystalline (e.g., Anatase- $\mathrm{TiO}_{2}$ ), and it may undergo continuous structural change or phase transition.

\section{Implications from nature: partition coefficient of element between the ocean and the Earth's crust}

Understanding oxide dissolutions is mostly based on experimental observations under conditions likely present in applications of interest and on timescales that can be managed experimentally. These conditions and timescales may not be sufficient for the intended applications, especially for timescales much longer than experimentally manageable. Nature provides a hint for understanding the long-term chemical durability of oxides in natural environments that cannot be replicated in a laboratory. In the Earth's natural environment, almost all elements undergo global cycling enabled by various geochemical processes. During these processes in an environment that involves the atmosphere, hydrosphere, biosphere, and lithosphere, some elements are dissolved in the ocean, and others precipitate out and are sequenced in the Earth's crust. This 
results in a partition of elements between Earth's crust and ocean. The dynamic cycling processes have occurred on Earth over the geological history since at least 3 billion years ago when the oceans were formed. Early Earth had a salinity of approximately 1.5-2 times the modern value [165], which was reduced to more or less today's values approximately 1 billion years ago and has remained remarkably stable since then [166]. Since the Great Oxidation Event $\sim 2.4$ billion years ago, the Earth's atmosphere and the ocean have been oxidized, with the oxygen concentration at least in the present level since $\sim 0.5$ billion years ago. Since the last great glacial maximum approximately 22,000 years ago, the salinity has remained within a few percent of today's value [167]. Given the active processes on the Earth over a long period of time, the inputs to and outputs from the oceans may be considered in a quasisteady state. If this assumption is valid, the elemental partition between the ocean and Earth's crust indicates the durability of an element in the environment.

The partition coefficient between the ocean and Earth's crust is defined as the logarithmic ratio of the average concentration of the element in the ocean $\left(\mathrm{Ca}_{\text {ocean }}\right)[168$, $169]$ and the average concentration in the Earth's crust $\left(\mathrm{Ca}_{\text {crust }}\right)$ [170]. For $\mathrm{Ca}, \log \left(\mathrm{Ca}_{\text {ocean }} / \mathrm{Ca}_{\text {crust }}\right)=\sim 2.0$, resulting in a partition of 100:1. In fact, calcium can be considered as a reference element because calcium carbonate (calcite or aragonite) is nearly in equilibrium with deep ocean water [171]. As shown in Fig. 10(a), the partition coefficient of all the elements with respect to $\mathrm{Ca}$ are plotted. The elements that are more partitioned in the ocean have positive values, suggesting they are less durable than calcium, and these elements include noble gasses, halogens, and most alkali and alkaline earth elements. Exceptions are observed for Be and Cs, which are expected to be soluble in aqueous solutions, but they are efficiently sequestered in the crust. These are probably due to high ioinic potential of $\mathrm{Be}^{2+}$ and adsorption of $\mathrm{Cs}^{+}$in silicate rockes. Because they have very negative values, they are chemically durable and depleted in the ocean, similar to many transition metal elements (TMs) and REEs. Re and Mo are less durable than most other transition metals. In terms of nuclear waste elements, soluble elements such as $\mathrm{Cl}, \mathrm{I}$, and $\mathrm{Sr}$, and those with durability similar to that of $\mathrm{Ca}$, such as $\mathrm{U}$ and Mo, become problematic radionuclides.

The residence time of an element in the ocean, the amount of the element in the ocean divided by the input or output rate, is a measure of how long, on average, the element remains in the ocean. If the residence time of an element is high, then the element is highly partitioned to the ocean. This leads to a positive correlation between the residence time and partition coefficient, as shown in Fig. 10(b). The top 15 major elements in the crust (cross-circles) and many trace elements are on the same trend. A linear fitting of the data $\left(R^{2}=0.82\right)$ results in the residence time $(\tau)$ :

$$
\tau=10^{7} \cdot\left(C_{\text {ocean }} / C_{\text {crust }}\right)^{0.6}
$$

Although silicon is the most abundant element in the Earth's crust and most rock-forming minerals are silicates, silica is undersaturated with respect to opal (amorphous silica) in sea water with $\log \left(C_{\text {ocean }} / C_{\text {crust }}\right) \sim-5[171,172,173]$, suggesting that $\mathrm{Si}$ is a durable element, which is consistent with observations. Using $\mathrm{Ca}$ and $\mathrm{Si}$ as two references for durability, all elements can be divided into three groups based on their residence time and partition coefficient, as shown in Fig. 10(b). Elements with a low partition coefficient $\left(\log \left(C_{\text {ocean }} / C_{\text {crust }}\right)<\right.$ $-5)$ and short residence time $(\log (\tau)<4.3$ or $\tau<20,000$ years) are elements sequestered in the ocean with high efficiency and high rate and are considered to be durable in the Earth's surface environment. Elements with high partition coefficients $\left(\log \left(C_{\text {ocean }} / C_{\text {crust }}\right)>-2\right)$ and long residence times $(\log (\tau)>6$ or $\tau>1,000,000$ years) are not durable, cannot be cycled by the Earth's crust, and remain mostly in ocean water. Those in between have intermediate durability. It is not surprising that corrosion-resistant elements such as $\mathrm{Cr}, \mathrm{Al}$, and $\mathrm{Ti}$ are located in the durable region [Fig. 10(b)]. REEs and many TMs are also located in the durable region. The elements $\mathrm{Cl}$, I, and $\mathrm{Sr}$ in the soluble region and $\mathrm{Cs}$ and $\mathrm{U}$ near the soluble region are problematic in nuclear waste management, and their behaviors in the environment are of great interest. As these data show, the Earth's natural processes have the ability to selectively sequester some elements in the crust, which provides a unique perspective in understanding the durability of oxides.

The residence time and partition coefficient have important implications for nuclear waste disposal. The idea of ocean disposal of radioactive waste was dismissed long time ago but resurfaces from time to time in the news. The mechanism for ocean dumping is based on the ocean's dilution ability to mitigate the hazardous effects to marine life [174]. There are many good reasons that dumping was banned. However, the ocean's ability to sequester elements has not been considered. For instance, the ocean can effectively recycle $\mathrm{Th}, \mathrm{Be}, \mathrm{Pd}$, and REEs in a time frame of thousands of years, while $\mathrm{Cl}$, I, and $\mathrm{Sr}$ can remain in the ocean for many millions of years. Therefore, the effects of dumping nuclear waste in the ocean need further study to understand the effect of dumping on the natural cycling of elements in the ocean. Such understanding could lead to a full appreciation of the intriguing coupling of anthropogenic activities and natural processes.

For ceramic nuclear waste forms, natural mineral analogues have been used for waste form development, such as the development of synroc [175]. These natural analogues demonstrate their durability in natural processes in geological time. One characteristic of these minerals is their flexibility in composition, which results from their crystal structure with 


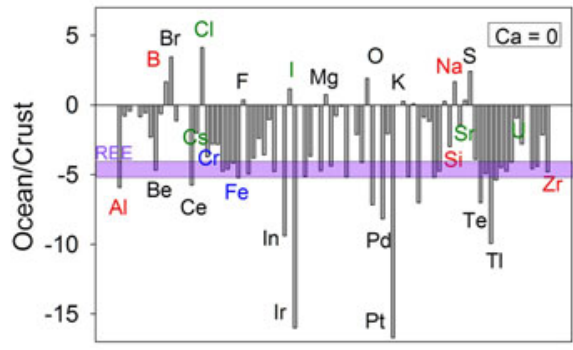

(a)

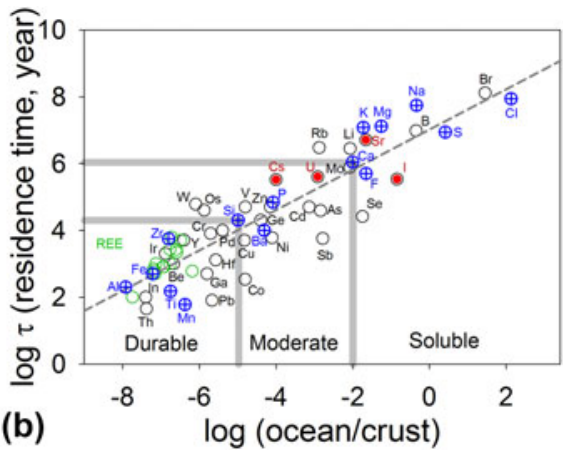

(b)

Figure 10: (a) The partition coefficient between the ocean and Earth's crust is plotted for all natural elements with respect to Ca. (b) Logarithm residence time is plotted as a function of the partition coefficient between the ocean and Earth's crust. The dashed line is the linear regression line. The thick gray lines divide the elements into three regions: durable, moderate, and soluble. Major elements in Earth's crust are blue crossed-circles.

multiple crystallographic sites that can be substituted with different elements of similar size and valance. Because chemical durability varies significantly from element to element, exploration of the compositional space of these natural analogues can be a fruitful area for research and development to optimize the composition of a given nuclear waste.

\section{Challenges and opportunities for predictive understanding of the dissolution kinetics of oxides}

(i) The dissolution rate is not an intrinsic property of a material but a response to the environmental conditions. Thus, the rate measured under arbitrary conditions cannot be used to quantify the chemical durability of the material. The chemical durability should be characterized by a collection of intrinsic properties that account for the response to environmental variables. A reliable prediction of the chemical durability of a material requires accurate estimations of these intrinsic properties. These properties include the forward rate constant, solubility constant, activation energy of temperature dependence, and reaction order $\mathrm{pH}$ dependence. Each of these intrinsic properties can be estimated from a series of experiments that are systematically designed for that environmental variable. However, it is desirable that these intrinsic properties are predicted from the composition and structure of the material. Although substantial experimental effort in the past decades has been dedicated to estimating some of these properties, only a few examples have been reported to predict some of these properties, such as the forward rate [86] and the reaction order $\mathrm{pH}$ dependence [176]. Systematic studies for predictive understanding of the variations in these intrinsic parameters within a group of materials and across different groups are essential for a quantitative prediction of the dissolution kinetics of materials from their structure and composition.

(ii) The forward rate constant or the far-from-equilibrium rate constant [i.e., $k_{0}$ in Eq. (14)] is an intrinsic property of a material and is often used as a parameter to quantify its chemical durability. However, in practice, at a given condition (e.g., $\mathrm{T}, \mathrm{pH}$, and solution composition), the forward rate [i.e., $k_{+}$in Eqs. (13) and (14)] is replaced with the initial rate, which is ill-defined and often not the same rate under the far-fromequilibrium condition. The problems of using the initial rate as the forward rate arise from the surface artifacts as a result of the sample preparation, grain boundaries, and how dissolution data points are selected to calculate the initial rate. In addition, in a static batch experiment, as soon as dissolved species are presented in the solution, the reverse reaction occurs. The effect of the reverse reaction on the dissolution rate highly depends on the properties of the material and the solution conditions. The contribution of the reverse reaction to the measured rate has not been rigorously treated in most experiments for the estimation of the initial rate. These issues cause inconsistencies in the forward rate estimations. Therefore, there is a need to develop a consistent method to exclude surface artifacts and solution feedback in estimating the initial rate. In addition, short-term screening tests such as static product consistency tests, which are often used for screening the durability of materials, cannot be used to quantify the chemical durability of a material because the resulting value is not an intrinsic property of the material. Research on how to relate these short-term test results to chemical durability is important to provide reliable guidance for the development of durable materials. 
(iii) One of the challenges of the current TST-SCM formulation is high or partial orders of the dependence of the rate on the concentrations of the surface complexes or solution species in the rate equations $[81,100,112,113,116,119]$. To derive rate equations, dissolution experiments are performed, and surface dissolution reactions are written based on reactive surface precursors informed by SCM, and then the reaction orders are determined by fitting the rate equations to the experimental observations.

Justifications of the orders are often based on assumptions of the surface-activated complex involved in the dissolution reactions. Although such a practice is useful in the modeling of experimental results, the fundamental mechanisms of the molecular-scale reaction pathways that lead to the reaction orders are left with speculations. Multiple dissolution mechanisms could be derived to fit the dissolutions data equally well with statistically indistinguishable numerical errors [177]. The problem may be compounded by the parameter dependence among the fitting variables, especially for small fractional reaction orders. To account for the partial orders, rate equations have been derived for a number of systems based on the coupling of detaching oppositely charged surface species through the electrostatic potential at the surfaces $[176,178,179]$. In many of these efforts to derive rate equations, a common challenge is the identity and stoichiometry of the surface complexes that lead to the dissolution reaction. Experimental techniques that are capable of detecting these surface species could provide direct support for the derivation of the rate equations. Computational methods such as free-energy methods based on electronic structure calculations and molecular dynamics simulations can not only compute the speciation and energetics of surface reactions but also provide a test of the proposed dissolution mechanisms.

One of the limitations of the current TST-SCM formulation is the effect of an external potential on the dissolution rate. Indeed, SCM has already accounted for the effect of the surface potential induced by charged surface species. However, if an external potential is applied, the concentrations of the surface complexes will change. For instance, the $\left[>\mathrm{MgOH}_{2}^{+}\right]$surface complex concentration will increase by an applied external negative potential, which can lead to increased dissolution because the doubly protonated surface complex controls brucite dissolution [Fig. 6(a)]. Such an enhanced dissolution was reported in a recent experiment, which showed that the dissolution rates of silica and alumina were increased by up to 2 orders of magnitude over the dissolution rates of isolated compositionally similar surfaces under otherwise identical conditions when the surface electrochemical properties were changed either by an applied potential or close to a dissimilar surface [180]. In addition, similar experimental results were also reported at interfaces between oxides and a metal [181]. The accelerated corrosion was attributed to the interfacial interactions between the dissimilar materials (stainless steel and a nuclear waste glass and a ceramic waste form). These results provide new insights on the dissolution processes that occur in confined spaces or under an applied field. Electrostatic potential as an additional environmental parameter provides opportunities to explore the dissolution phenomena of various materials under various scenarios for diverse applications.

(iv) Predictions of the dissolution rate of oxides on short timescales can be directly verified with additional experimental observations. Great challenges remain in reliably predicting the long-term durability that is more relevant for many applications. In practice, long-term prediction of the dissolution rate relies on determining all the critical reaction kinetics that are rate determining in dissolution. In reality, however, such an approach cannot guarantee that all rate-determining reactions are inclusively identified and characterized. For instance, the secondary phase formation in the dissolution of many silicates greatly complicates the understanding of the longterm dissolution kinetics. This complication arises from the complex nature of nucleation and growth of the secondary phases and their phase transformation over time. In some cases, the transformation is continuous, such as the amorphous gel-like alteration layer on many silicates, which may experience gradual coordination changes in a short timescale and eventually transform to the thermodynamic more stable phases, such as zeolite and clays. There is a need to predict the types of the secondary phases, the formation rate of the secondary phases, and the effect on the dissolution kinetics of the material. In addition, it might be worth exploring the degradation of ancient objects (e.g., man-made and natural materials) and minerals of sediments in geological records for benchmarking the prediction of the long-term dissolution rate as long as their age and the environmental conditions they experienced can be quantified.

(v) Surface alteration layers have a great effect on the dissolution kinetics of many multiple-metal oxides including silicates. However, experimental observations have shown that not all alteration layers at surfaces are passivating [33]. The properties that prevent the materials from further dissolution mainly rest on the 
microstructure of the layer. Currently, there is a lack of a theory on what properties of a material and what environmental conditions determine the passivating properties. Both experimental and molecular modeling have been employed to understand the microstructure and the transport of aqueous species in the alteration layer [33, 155, 160]. Additional research is needed to understand how the underlying solid structure and environmental conditions control the microstructure and the transport properties of the reacting aqueous species in the surface alteration layers. For a given crystalline material, the passivation of different crystal faces is expected to be different because of different surface structures. Investigations into how the underlying crystal structure constrains the formation of different microstructures in the alteration layer could lead to a better understanding of the alteration layer formation.

(vi) Dissolution experiments have been reported for a large number of materials without quantifying defects as a controlling property that affects dissolution. Although experimental observations have shown defects have a significant effect on the dissolution rates of oxides, how different types of defects affect the dissolution rate has not been systematically investigated and their effect on dissolution kinetics has not been rigorously formulated. One exception is that the effect of dislocation, which is quantified by a critical free energy ( $\Delta G_{\text {crit }}$ ) for opening up etch pits that accelerate the dissolution using a dissolution stepwave model [56]. There are many other different types of defects, such as vacancies, interstitials, Frenkel pairs (point defects), edge and screw dislocations (linear defects), grain boundaries, stacking faults, antiphase boundaries, twin boundaries (planar defects), pores, voids, and impurity clusters such as precipitates (bulk defects). Defects can also be introduced by radioactive elements. The $\beta$-emitting elements in oxides can change the chemical composition over time as a result of $\beta$ decay, which could have a significant effect on the chemical durability. The $\alpha$-emitting actinides in oxides can induce radiation damage, which also affect the chemical durability. Research on both of these areas will provide a fundamental understanding of how nuclear waste forms degrade over long timescales. There is also a need to quantify defects in amorphous oxides such as glasses. In these materials, defects do exist. For instance, if short-range order is considered for ideal amorphous $\mathrm{SiO}_{2}$, then each $\mathrm{Si}$ is coordinated to $4 \mathrm{O}$ and each $\mathrm{O}$ is coordinated to two Si. A single coordinated $\mathrm{O}$ and 3 or 5 coordinated $\mathrm{Si}$ can be considered as defects in silica. Such a consideration is very similar in defining defects in crystals and the properties of these defects in silica are expected to be similar to vacancies and interstitials in crystals.

(vii) Cold sintering is a technique to synthesize dense monolith ceramics by adding a small volume of liquid (e.g., water) to the starting powder to provide a medium for mass transport (dissolution, precipitation, and growth) that is assisted by applying pressure and heat at temperatures below $400{ }^{\circ} \mathrm{C}$. The technique has been successfully demonstrated for a number of ceramic systems to produce high theoretical density dense monoliths with low cost and high efficiency. The main processes of sintering include the mechanical compaction of the powder, cementation between particles, and reduction of voids enabled by a combination of homogeneous and heterogeneous precipitation events on existing and newly formed grains. During the process, hydrated phases may form, and surfaces and grain boundaries may be hydroxylated and remain in the ceramics. The increased concentration of these hydrous species (hydroxyl, water, and hydrogen) may change the properties of the ceramics with respect to the anhydrous ceramics. The chemical durability may be increased. In fact, many hydrous minerals have much lower dissolution rates than the anhydrous ones, in part because of the increased chemical potentials of the water species in hydrous phases. The changes in properties as a result of cold sintering ceramics, such as the chemical durability, need to be studied in the future.

\section{Acknowledgment}

This work was supported as part of the Center for Performance and Design of Nuclear Waste Forms and Containers, an Energy Frontier Research Center funded by the U.S. Department of Energy, Office of Science, Basic Energy Sciences, under Award DE-SC0016584.

\section{References}

1. G.S. Frankel, J.D. Vienna, J. Lian, J.R. Scully, S. Gin, J.V. Ryan, J. Wang, S.H. Kim, W. Windl, and J. Du: A comparative review of the aqueous corrosion of glasses, crystalline ceramics, and metals. npj Mater. Degrad. 2, 15 (2018).

2. R.C. Ewing and L. Wang: Phosphates as nuclear waste forms. Rev. Mineral. Geochem. 48, 673 (2002).

3. R.A. Berner: Rate control of mineral dissolution under earth surface conditions. Am. J. Sci. 278, 1235 (1978). 
4. P. Aagaard and H.C. Helgeson: Thermodynamic and kinetic constraints on reaction-rates among minerals and aqueoussolutions (I) theoretical considerations. Am. J. Sci. 282, 237 (1982).

5. Stumm W. and E. Wieland, Dissolution of oxide and silicate minerals: Rates depend on surface speciation, in Aquatic chemical kinetics: Reaction rates of processes in natural waters, W. Stumm, Editor. (1990), Wiley-Interscience. pp. 367-400.

6. W. Stumm and R. Wollast: Coordination chemistry of weathering: Kinetics of the surface-controlled dissolution of oxide minerals. Rev. Geophys. 28, 53 (1990).

7. W.B. White: Theory of corrosion of glass and ceramics. In Corrosion of Glass, Ceramics and Ceramic Superconductors: Principles, Testing, Characterization and Applications, D.E. Clark and B.K. Zoitos, eds. (Noyes Publications, Park Ridge, NJ, 1992); p. 2.

8. A.C. Lasaga: Fundamental approaches in describing mineral dissolution and precipitation rates. Rev. Mineral. Geochem. 31, 23 (1995).

9. S.L. Brantley: Kinetics of mineral dissolution. In Kinetics of Water-Rock Interaction (Springer, New York, NY, 2008); p. 151.

10. J. Schott, O.S. Pokrovsky, and E.H. Oelkers: The link between mineral dissolution/precipitation kinetics and solution chemistry. Rev. Mineral. Geochem. 70, 207 (2009).

11. I.G. Gorichev and N.A. Kipriyanov: Regular kinetic features of the dissolution of metal oxides in acidic media. Russ. Chem. Rev. 53, 1039 (1984).

12. M.A. Blesa: Chemical Dissolution of Metal Oxides, 1st ed. (CRC Press, Boca Raton, FL, 1994); p. 434.

13. D. Suter, S. Banwart, and W. Stumm: Dissolution of hydrous iron(III) oxides by reductive mechanisms. Langmuir 7, 809 (1991).

14. A.T. Stone: Reductive dissolution of manganese(III/IV) oxides by substituted phenols. Environ. Sci. Technol. 21, 979 (1987).

15. B. Zinder, G. Furrer, and W. Stumm: The coordination chemistry of weathering: II. Dissolution of Fe(III) oxides. Geochim. Cosmochim. Acta 50, 1861 (1986).

16. Z. Wang, S-W. Lee, P. Kapoor, B.M. Tebo, and D.E. Giammar: Uraninite oxidation and dissolution induced by manganese oxide: A redox reaction between two insoluble minerals. Geochim. Cosmochim. Acta 100, 24 (2013).

17. A.F. White, M.L. Peterson, and M.F. Hochella:

Electrochemistry and dissolution kinetics of magnetite and ilmenite. Geochim. Cosmochim. Acta 58, 1859 (1994).

18. F.C. Richard and A.C. Bourg: Aqueous geochemistry of chromium: A review. Water Res. 25, 807 (1991).

19. B. Dhal, H.N. Thatoi, N.N. Das, and B.D. Pandey: Chemical and microbial remediation of hexavalent chromium from contaminated soil and mining/metallurgical solid waste: A review. J. Hazard. Mater. 250-251, 272 (2013).

20. S. Kuppusamy, T. Palanisami, M. Megharaj, K. Venkateswarlu, and R. Naidu: In situ remediation approaches for the management of contaminated sites: A comprehensive overview.
In Reviews of Environmental Contamination and Toxicology, Vol. 236, P. de Voogt, ed. (Springer International Publishing, Basel, Switzerland, 2016); p. 1.

21. B.R. James: Remediation-by-reduction strategies for chromatecontaminated soils. Environ. Geochem. Health 23, 175 (Society for Environmental Geochemistry and Health, Springer, 2001).

22. R. Nickson, J. McArthur, W. Burgess, K.M. Ahmed,

P. Ravenscroft, and M. Rahmanñ: Arsenic poisoning of Bangladesh groundwater. Nature 395, 338 (1998).

23. R.S. Oremland and J.F. Stolz: Arsenic, microbes, and contaminated aquifers. Trends Microbiol. 13, 45 (2005).

24. R. Shannon: Revised effective ionic radii and systematic studies of interatomic distances in halides and chalcogenides. Acta Crystallogr. A 32, 751 (1976).

25. G. Cartledge: Studies on the periodic system. I. The ionic potential as a periodic function. J. Am. Chem. Soc. 50, 2855 (1928).

26. G. Cartledge: Studies on the periodic system. II. The ionic potential and related properties. J. Am. Chem. Soc. 50, 2863 (1928).

27. V.M. Goldschmidt: The principles of distribution of chemical elements in minerals and rocks. The seventh Hugo Müller lecture, delivered before the chemical society on March 17 th, 1937. J. Chem. Soc., 1927, 655-673 (1937).

28. J. Chorover and M.L. Brusseau: Kinetics of sorption desorption. In Kinetics of Water-Rock Interaction, S.L. Brantley, J.D. Kubicki, and A.F. White, eds. (Springer New York, 2008); p. 109.

29. Z. Zhang, A. Heath, K.T. Valsaraj, W.L. Ebert, T. Yao, J. Lian, and J. Wang: Mechanism of iodine release from iodoapatite in aqueous solution. RSC Adv. 8, 3951 (2018).

30. Z. Zhang, L. Gustin, W. Xie, J. Lian, K.T. Valsaraj, and J. Wang: Effect of solution chemistry on the iodine release from iodoapatite in aqueous environments. J. Nucl. Mater. 525, 161 (2019).

31. Z. Zhang, W.L. Ebert, T. Yao, J. Lian, K.T. Valsaraj, and J. Wang: Chemical durability and dissolution kinetics of iodoapatite in aqueous solutions. ACS Earth Space Chem. 3, 452 (2019).

32. S. Gin, P. Jollivet, M. Tribet, S. Peuget, and S. Schuller: Radionuclides containment in nuclear glasses: An overview. Radiochim. Acta 105, 927 (2017).

33. J. Schott, O.S. Pokrovsky, O. Spalla, F. Devreux, A. Gloter, and J.A. Mielczarski: Formation, growth, and transformation of leached layers during silicate minerals dissolution: The example of wollastonite. Geochim. Cosmochim. Acta 98, 259 (2012).

34. J.C. Phillips: Topology of covalent non-crystalline solids I: Shortrange order in chalcogenide alloys. J. Non-Cryst. Solids 34, 153 (1979).

35. M.F. Thorpe: Continuous deformations in random networks. J. Non-Cryst. Solids 57, 355 (1983). 
36. J.C. Mauro: Topological constraint theory of glass. Am. Ceram. Soc. Bull. 90, 31 (2011).

37. M.M. Smedskjaer, J.C. Mauro, R.E. Youngman, C.L. Hogue, M. Potuzak, and Y. Yue: Topological principles of borosilicate glass chemistry. J. Phys. Chem. B 115, 12930 (2011).

38. I. Pignatelli, A. Kumar, M. Bauchy, and G. Sant: Topological control on silicates' dissolution kinetics. Langmuir 32, 4434 (2016).

39. N. Mascaraque, M. Bauchy, and M.M. Smedskjaer: Correlating the network topology of oxide glasses with their chemical durability. J. Phys. Chem. B 121, 1139 (2017).

40. P. Armentrout, L. Halle, and J. Beauchamp: Periodic trends in transition metal-hydrogen, metal-carbon, and metal-oxygen bond dissociation energies. Correlation with reactivity and electronic structure. J. Am. Chem. Soc. 103, 6501 (1981).

41. K. Johnson and S. Pepper: Molecular-orbital model for metalsapphire interfacial strength. J. Appl. Phys. 53, 6634 (1982).

42. D. Rethwisch and J. Dumesic: The effects of metal-oxygen bond strength on properties of oxides: II. Water-gas shift over bulk oxides. Appl. Catal. 21, 97 (1986).

43. E. Wieland, B. Wehrli, and W. Stumm: The coordination chemistry of weathering: III. A generalization on the dissolution rates of minerals. Geochim. Cosmochim. Acta 52, 1969 (1988).

44. M.A. Velbel: Bond strength and the relative weathering rates of simple orthosilicates. Am. J. Sci. 299, 679 (1999).

45. E.H. Oelkers: General kinetic description of multioxide silicate mineral and glass dissolution. Geochim. Cosmochim. Acta 65, 3703 (2001).

46. I.D. Brown: Recent developments in the methods and applications of the bond valence model. Chem. Rev. 109, 6858 (2009).

47. K.H. Sun: Fundamental condition of glass formation. J. Am. Ceram. Soc. 30, 277 (1947).

48. G. Lusvardi, G. Malavasi, F. Tarsitano, L. Menabue, M.C. Menziani, and A. Pedone: Quantitative structure-property relationships of potentially bioactive fluoro phospho-silicate glasses. J. Phys. Chem. B 113, 10331 (2009).

49. X. Lu, L. Deng, S. Gin, and J. Du: Quantitative structureproperty relationship (QSPR) analysis of $\mathrm{ZrO}_{2}$-containing sodalime borosilicate glasses. J. Phys. Chem. B 123, 1412 (2019).

50. W. Bollmann: Crystal Defects and Crystalline Interfaces, 2nd ed. (Springer Science \& Business Media, 2012).

51. H. Scholze: Glass: Nature, Structure, and Properties (Springer Science \& Business Media, 1991).

52. G. Greaves and S. Sen: Inorganic glasses, glass-forming liquids and amorphizing solids. Adv. Phys. 56, 1 (2007).

53. J.D. Martin, S.J. Goettler, N. Fossé, and L. Iton: Designing intermediate-range order in amorphous materials. Nature 419, 381 (2002).

54. H.M. Burt and A. Mitchell: Crystal defects and dissolution. Int. J. Pharm. 9, 137 (1981).
55. D. Guo, C. Robinson, and J.E. Herrera: Role of $\mathrm{Pb}(\mathrm{II})$ defects in the mechanism of dissolution of plattnerite $\left(\beta-\mathrm{PbO}_{2}\right)$ in water under depleting chlorine conditions. Environ. Sci. Technol. 48, 12525 (2014)

56. A.C. Lasaga and A. Luttge: Variation of crystal dissolution rate based on a dissolution stepwave model. Science 291, 2400 (2001).

57. J. Schott, S. Brantley, D. Crerar, C. Guy, M. Borcsik, and C. Willaime: Dissolution kinetics of strained calcite. Geochim. Cosmochim. Acta 53, 373 (1989).

58. I.N. MacInnis and S.L. Brantley: The role of dislocations and surface morphology in calcite dissolution. Geochim. Cosmochim. Acta 56, 1113 (1992).

59. A.E. Blum, R.A. Yund, and A.C. Lasaga: The effect of dislocation density on the dissolution rate of quartz. Geochim. Cosmochim. Acta 54, 283 (1990).

60. J.N. Clark, J. Ihli, A.S. Schenk, Y-Y. Kim, A.N. Kulak, J.M. Campbell, G. Nisbet, F.C. Meldrum, and I.K. Robinson: Three-dimensional imaging of dislocation propagation during crystal growth and dissolution. Nat. Mater. 14, 780 (2015)

61. H. He, J. Cao, and N. Duan: Defects and their behaviors in mineral dissolution under water environment: A review. Sci. Total Environ. 651, 2208 (2019).

62. C.L. Corkhill, D.J. Bailey, F.Y. Tocino, M.C. Stennett, J.A. Miller, J.L. Provis, K.P. Travis, and N.C. Hyatt: Role of microstructure and surface defects on the dissolution kinetics of $\mathrm{CeO}_{2}$, a $\mathrm{UO}_{2}$ fuel analogue. ACS Appl. Mater. Interfaces 8, 10562 (2016).

63. A.J. Popel, T.W. Wietsma, M.H. Engelhard, A.S. Lea, O. Qafoku, C. Grygiel, I. Monnet, E.S. Ilton, M.E. Bowden, and I. Farnan: The effect of ion irradiation on the dissolution of $\mathrm{UO}_{2}$ and $\mathrm{UO}_{2}$-based simulant fuel. J. Alloys Compd. 735, 1350 (2018).

64. B.D. Begg, N.J. Hess, W.J. Weber, R. Devanathan, J.P. Icenhower, S. Thevuthasan, and B.P. McGrail: Heavy-ion irradiation effects on structures and acid dissolution of pyrochlores. J. Nucl. Mater. 288, 208 (2001).

65. Y. Maeda, K. Fukami, S. Kondo, A. Kitada, K. Murase, and T. Hinoki: Irradiation-induced point defects enhance the electrochemical activity of $3 \mathrm{C}-\mathrm{SiC}$ : An origin of $\mathrm{SiC}$ corrosion. Electrochem. Commun. 91, 15 (2018).

66. S. Kondo, S. Mouri, Y. Hyodo, T. Hinoki, and F. Kano: Role of irradiation-induced defects on $\mathrm{SiC}$ dissolution in hot water. Corros. Sci. 112, 402 (2016).

67. L. Beaunier: Corrosion of grain boundaries: Initiation processes and testing. J. Phys. 43, C6 (1982).

68. X. Liu, J. Shao, G. Cragnolino, and D. Macdonald: Selective grain-boundary dissolution of alloy 600 in a concentrated caustic solution at $140{ }^{\circ}$ C. J. Mater. Energy Syst. 7, 223 (1985).

69. R. Podor, X. Le Goff, T. Cordara, M. Odorico, J. Favrichon, L. Claparede, S. Szenknect, and N. Dacheux: 3D-SEM height maps series to monitor materials corrosion and dissolution. Mater. Charact. 150, 220 (2019). 
70. A. Klemm, M. Gomez-Florit, P.A. Carvalho, M. Wachendörfer, M.E. Gomes, H.J. Haugen, and H. Tiainen: Grain boundary corrosion in $\mathrm{TiO}_{2}$ bone scaffolds doped with group II cations. J. Eur. Ceram. Soc. 39, 1577 (2019).

71. E. Grunwald and S. Winstein: The correlation of solvolysis rates. J. Am. Chem. Soc. 70, 846 (1948).

72. L.P. Hammett: The effect of structure upon the reactions of organic compounds. Benzene derivatives. J. Am. Chem. Soc. 59, 96 (1937).

73. C.G. Swain and C.B. Scott: Quantitative correlation of relative rates. Comparison of hydroxide ion with other nucleophilic reagents toward alkyl halides, esters, epoxides, and acyl halides1. J. Am. Chem. Soc. 75, 141 (1953).

74. F.P. Rotzinger: Structure of the transition states and intermediates formed in the water-exchange of metal hexaaqua ions of the first transition series. J. Am. Chem. Soc. 118, 6760 (1996).

75. F.P. Rotzinger: Mechanism of water exchange for the di-and trivalent metal hexaaqua ions of the first transition series. J. Am. Chem. Soc. 119, 5230 (1997).

76. D.T. Richens: The Chemistry of Aqua Ions, Synthesis, Structure and Reactivity (Wiley, Chichester, 1997).

77. L. Helm and A. Merbach: Water exchange on metal ions: Experiments and simulations. Coord. Chem. Rev. 187, 151 (1999).

78. S.F. Lincoln: Mechanistic studies of metal aqua ions: A semihistorical perspective. Helv. Chim. Acta 88, 523 (2005).

79. B. Wehrli: Redox reactions of metal ions at mineral surfaces. In Aquatic Chemical Kinetics: Reaction Rates of Processes in Natural Waters. Environmental Science Technology Series Stumm, Werner, ed. (John Wiley Sons, New York, 1990); p. 311.

80. W.H. Casey: On the relative dissolution rates of some oxide and orthosilicate minerals. J. Colloid Interface Sci. 146, 586 (1991).

81. O. Pokrovsky and J. Schott: Surface chemistry and dissolution kinetics of divalent metal carbonates. Environ. Sci. Technol. 36, 426 (2002).

82. W.H. Casey and T.W. Swaddle: Why small? The use of small inorganic clusters to understand mineral surface and dissolution reactions in geochemistry. Rev. Geophys. 41, 1008 (2003).

83. J.S. Griffith and L.E. Orgel: Ligand-field theory. Q. Rev. Chem. Soc. 11, 381 (1957).

84. C.K. Jørgensen: Recent progress in ligand field theory. In Structure and Bonding (Springer, 1966); p. 3.

85. D.A. Sverjensky and P.A. Molling: A linear free energy relationship for crystalline solids and aqueous ions. Nature 356, 231 Springer, Berlin, Heidelberg, (1992).

86. D.A. Sverjensky: Linear free energy relations for predicting dissolution rates of solids. Nature 358, 310 (1992).

87. A.J. Ragavan and D.V. Adams: Estimating free energies of formation of titanate $\left(\mathrm{M}_{2} \mathrm{Ti}_{2} \mathrm{O}_{7}\right)$ and zirconate $\left(\mathrm{M}_{2} \mathrm{Zr}_{2} \mathrm{O}_{7}\right)$ pyrochlore phases of trivalent lanthanides and actinides. Mater. Sci. 2011, 680785 (2011).

88. H. Xu and Y. Wang: Use of linear free energy relationship to predict Gibbs free energies of formation of zirconolite phases $\left(\mathrm{MZrTi}_{2} \mathrm{O}_{7}\right.$ and $\mathrm{MHfTi}_{2} \mathrm{O}_{7}$ ). J. Nucl. Mater. 275, 211 (1999).

89. $\mathrm{H}$. Xu and Y. Wang: Use of linear free energy relationship to predict Gibbs free energies of formation of pyrochlore phases $\left(\mathrm{CaMTi}_{2} \mathrm{O}_{7}\right)$. J. Nucl. Mater. 275, 216 (1999).

90. H. Xu, Y. Wang, and L.L. Barton: Application of a linear free energy relationship to crystalline solids of $\mathrm{MO}_{2}$ and $\mathrm{M}(\mathrm{OH})_{4} . J$. Nucl. Mater. 273, 343 (1999).

91. L.P. Hammett: Some relations between reaction rates and equilibrium constants. Chem. Rev. 17, 125 (1935).

92. Y. Yang, Y. Min, J. Lococo, and Y-S. Jun: Effects of Al/Si ordering on feldspar dissolution: Part I. Crystallographic control on the stoichiometry of dissolution reaction. Geochim. Cosmochim. Acta 126, 574 (2014).

93. Y. Yang, Y. Min, and Y-S. Jun: Effects of $\mathrm{Al} / \mathrm{Si}$ ordering on feldspar dissolution: Part II. The $\mathrm{pH}$ dependence of plagioclases' dissolution rates. Geochim. Cosmochim. Acta 126, 595 (2014).

94. G. Furrer and W. Stumm: The coordination chemistry of weathering: I. Dissolution kinetics of $\delta-\mathrm{Al}_{2} \mathrm{O}_{3}$ and $\mathrm{BeO}$. Geochim. Cosmochim. Acta 50, 1847 (1986).

95. A. Blum and A. Lasaga: Role of surface speciation in the lowtemperature dissolution of minerals. Nature 331, 431 (1988).

96. J. Westall and H. Hohl: A comparison of electrostatic models for the oxide/solution interface. Adv. Colloid Interface Sci. 12, 265 (1980).

97. G. Sposito: On the surface complexation model of the oxideaqueous solution interface. J. Colloid Interface Sci. 91, 329 (1983).

98. H.C. Helgeson, W.M. Murphy, and P. Aagaard:

Thermodynamic and kinetic constraints on reaction-rates among minerals and aqueous-solutions. II. Rate constants, effective surface-area, and the hydrolysis of feldspar. Geochim. Cosmochim. Acta 48, 2405 (1984).

99. W.M. Murphy and H.C. Helgeson: Thermodynamic and kinetic constraints on reaction-rates among minerals and aqueoussolutions. III. Activated complexes and the $\mathrm{pH}$-dependence of the rates of feldspar, pyroxene, wollastonite, and olivine hydrolysis. Geochim. Cosmochim. Acta 51, 3137 (1987).

100. O.S. Pokrovsky and J. Schott: Experimental study of brucite dissolution and precipitation in aqueous solutions: Surface speciation and chemical affinity control. Geochim. Cosmochim. Acta 68, 31 (2004).

101. C. Guy and J. Schott: Multisite surface reaction versus transport control during the hydrolysis of a complex oxide. Chem. Geol. 78, 181 (1989)

102. J. Schott: Modeling of the dissolution of strained and unstrained multiple oxides: The surface speciation approach. In Aquatic Chemical Kinetics, W. Stumm, ed. (John Wiley \& Sons, New York, 1990); p. 337. 
103. C. Ludwig and W.H. Casey: On the mechanisms of dissolution of bunsenite $[\mathrm{NiO}(\mathrm{s})]$ and other simple oxide minerals. J. Colloid Interface Sci. 178, 176 (1996).

104. J. Wang, A.G. Kalinichev, and R.J. Kirkpatrick: Molecular modeling of water structure in nano-pores between brucite (001) surfaces. Geochim. Cosmochim. Acta 68, 3351 (2004).

105. R. Wollast and L. Chou: Rate control of weathering of silicate minerals at room temperature and pressure. In Physical and Chemical Weathering in Geochemical Cycles (Springer, Dordrecht, 1988); p. 11.

106. T. Hiemstra and W. Van Riemsdijk: Multiple activated complex dissolution of metal (hydr) oxides: A thermodynamic approach applied to quartz. J. Colloid Interface Sci. 136, 132 (1990).

107. G. Berger, E. Gadore, J. Schott, and M. Dove: Dissolution rate of quartz in $\mathrm{Pb}$ and $\mathrm{Na}$ electrolyte solutions. Effect of interaction pattern and reaction affinity. Geochim. Cosmochim. Acta 58, 541 (1994).

108. S.A. Carroll-Webb and J. Walther: A surface complex reaction model for the $\mathrm{pH}$-dependence of corundum and kaolinite dissolution rates. Geochim. Cosmochim. Acta 52, 2609 (1988).

109. P. Bénézeth, D.A. Palmer, and D.J. Wesolowski: Dissolution/ precipitation kinetics of boehmite and gibbsite: Application of a $\mathrm{pH}$-relaxation technique to study near-equilibrium rates. Geochim. Cosmochim. Acta 72, 2429 (2008).

110. R. Wollast: Rate and mechanism of dissolution of carbonates in the system $\mathrm{CaCO}_{3}-\mathrm{MgCO}_{3}$. In Aquatic Chemical Kinetics: Reaction Rates of Processes in Natural Waters. Environmental Science and Technology Series Stumm, Werner, ed. (John Wiley \& Sons, New York, 1990); p. 431.

111. L. Plummer, T. Wigley, and D. Parkhurst: The kinetics of calcite dissolution in $\mathrm{CO}_{2}$-water systems at 5 degrees to 60 degrees $\mathrm{C}$ and 0.0 to $1.0 \mathrm{~atm} \mathrm{CO}_{2}$. Am. J. Sci. 278, 179 (1978).

112. O.S. Pokrovsky and J. Schott: Processes at the magnesiumbearing carbonates/solution interface. II. Kinetics and mechanism of magnesite dissolution. Geochim. Cosmochim. Acta 63, 881 (1999).

113. M. Gautelier, J. Schott, and E.H. Oelkers: An experimental study of dolomite dissolution rates at $80^{\circ} \mathrm{C}$ as a function of chemical affinity and solution composition. Chem. Geol. 242, 509 (2007).

114. E.H. Oelkers, S.V. Golubev, C. Chairat, O.S. Pokrovsky, and

J. Schott: The surface chemistry of multi-oxide silicates. Geochim. Cosmochim. Acta 73, 4617 (2009).

115. S.L. Brantley and L. Stillings: Feldspar dissolution at $25^{\circ} \mathrm{C}$ and low pH. Am. J. Sci. 296, 101 (1996).

116. E.H. Oelkers, J. Schott, and J-L. Devidal: The effect of aluminum, $\mathrm{pH}$, and chemical affinity on the rates of aluminosilicate dissolution reactions. Geochim. Cosmochim. Acta 58, 2011 (1994).

117. K.G. Knauss and T.J. Wolery: Dependence of albite dissolution kinetics on $\mathrm{pH}$ and time at $25{ }^{\circ} \mathrm{C}$ and $70{ }^{\circ} \mathrm{C}$. Geochem. Cosmochim. Acta 50, 2481 (1986).
118. L. Chou and R. Wollast: Steady-state kinetics and dissolution mechanisms of albite. Am. J. Sci. 285, 963 (1985).

119. J-M. Gautier, E.H. Oelkers, and J. Schott: Experimental study of $\mathrm{K}$-feldspar dissolution rates as a function of chemical affinity at $150{ }^{\circ} \mathrm{C}$ and pH 9. Geochim. Cosmochim. Acta 58, 4549 (1994).

120. J-L. Devidal, J. Schott, and J-L. Dandurand: An experimental study of kaolinite dissolution and precipitation kinetics as a function of chemical affinity and solution composition at $150{ }^{\circ} \mathrm{C}, 40$ bars, and $\mathrm{pH} 2,6.8$, and 7.8. Geochim. Cosmochim. Acta 61, 5165 (1997).

121. S.A. Carroll and K.G. Knauss: Dependence of labradorite dissolution kinetics on $\mathrm{CO}_{2}(\mathrm{aq}), \mathrm{Al}(\mathrm{aq})$, and temperature. Chem. Geol. 217, 213 (2005).

122. E.H. Oelkers, J. Schott, J-M. Gauthier, and T. Herrero-Roncal: An experimental study of the dissolution mechanism and rates of muscovite. Geochim. Cosmochim. Acta 72, 4948 (2008)

123. D. Wolff-Boenisch, S.R. Gislason, E.H. Oelkers, and C.V. Putnis: The dissolution rates of natural glasses as a function of their composition at $\mathrm{pH} 4$ and 10.6, and temperatures from 25 to $74{ }^{\circ} \mathrm{C}$. Geochem. Cosmochim. Acta 68, 4843 (2004).

124. E.H. Oelkers and S.R. Gislason: The mechanism, rates and consequences of basaltic glass dissolution: I. An experimental study of the dissolution rates of basaltic glass as a function of aqueous $\mathrm{Al}, \mathrm{Si}$ and oxalic acid concentration at $25^{\circ} \mathrm{C}$ and $\mathrm{pH}=3$ and 11. Geochim. Cosmochim. Acta 65, 3671 (2001).

125. E.H. Oelkers: An experimental study of forsterite dissolution rates as a function of temperature and aqueous $\mathrm{Mg}$ and $\mathrm{Si}$ concentrations. Chem. Geol. 175, 485 (2001).

126. A.C. Lasaga: Chemical kinetics of water-rock interactions. $J$. Geophys. Res.: Solid Earth 89, 4009 (1984).

127. S.R. Gislason and E.H. Oelkers: Mechanism, rates, and consequences of basaltic glass dissolution: II. An experimental study of the dissolution rates of basaltic glass as a function of $\mathrm{pH}$ and temperature. Geochim. Cosmochim. Acta 67, 3817 (2003).

128. P. Frugier, S. Gin, Y. Minet, T. Chave, B. Bonin, N. Godon, J-E. Lartigue, P. Jollivet, A. Ayral, and L. De Windt: SON68 nuclear glass dissolution kinetics: Current state of knowledge and basis of the new GRAAL model. J. Nucl. Mater. 380, 8 (2008).

129. K. Nagy, A. Blum, and A. Lasaga: Dissolution and precipitation kinetics of kaolinite at $80^{\circ} \mathrm{C}$ and $\mathrm{pH} 3$; the dependence on solution saturation state. Am. J. Sci. 291, 649 (1991).

130. K.L. Nagy and A.C. Lasaga: Dissolution and precipitation kinetics of gibbsite at $80{ }^{\circ} \mathrm{C}$ and $\mathrm{pH}$ 3: The dependence on solution saturation state. Geochim. Cosmochim. Acta 56, 3093 (1992).

131. G. Berger, E. Cadore, J. Schott, and P.M. Dove: Dissolution rate of quartz in lead and sodium electrolyte solutions between 25 and $300{ }^{\circ} \mathrm{C}$ : Effect of the nature of surface complexes and reaction affinity. Geochim. Cosmochim. Acta 58, 541 (1994).

132. P.M. Dove and N. Han: Kinetics of mineral dissolution and growth as reciprocal microscopic surface processes across 
chemical driving force. In AIP Conference Proceedings, Vol. 916 (American Institute of Physics, College Park, MD, 2007); p. 215.

133. A. Bouissonnié, D. Daval, M. Marinoni, and P. Ackerer: From mixed flow reactor to column experiments and modeling: Upscaling of calcite dissolution rate. Chem. Geol. 487, 63 (2018).

134. V.P. Isupov: Production of active aluminum hydroxide by intercalation-deintercalation of lithium salts. Russ. J. Appl. Chem. 69, 9 (1996).

135. L.B. Railsback. Some fundamentals of mineralogy and geochemistry. On-line book, quoted from: www.gly.uga.edu/railsback. (2006).

136. R. Li, W. Yang, Y. Su, Q. Li, S. Gao, and J.K. Shang: Ionic potential: A general material criterion for the selection of highly efficient arsenic adsorbents. J. Mater. Sci. Technol. 30, 949 (2014).

137. W. Dell, P. Bray, and S. Xiao: 11B NMR studies and structural modeling of $\mathrm{Na}_{2} \mathrm{O}-\mathrm{B}_{2} \mathrm{O}_{3}-\mathrm{SiO}_{2}$ glasses of high soda content. $J$. Non-Cryst. Solids 58, 1 (1983).

138. R. Conradt: Chemical structure, medium range order, and crystalline reference state of multicomponent oxide liquids and glasses. J. Non-Cryst. Solids 345, 16 (2004).

139. R. Conradt: Chemical durability of oxide glasses in aqueous solutions: A review. J. Am. Ceram. Soc. 91, 728 (2008).

140. B.P. McGrail, J. Icenhower, J. Darab, D. Shuh, D. Baer, V. Shutthanandan, S. Thevuthasan, M. Engelhard, J. Steele, and E. Rodriguez: Ion-exchange Processes and Mechanisms in Glasses (Pacific Northwest Laboratory, Richland, WA 2001); p. 9.

141. C.M. Jantzen and K.G. Brown: Predicting the spinel-nepheline liquidus for application to nuclear waste glass processing. Part I: Primary phase Analysis, liquidus measurment, and quasicrystalline approach. J. Am. Ceram. Soc. 90, 1866 (2007)

142. J. Mavračić, F.C. Mocanu, V.L. Deringer, G.b. Csányi, and S.R. Elliott: Similarity between amorphous and crystalline phases: The case of $\mathrm{TiO}_{2}$. J. Phys. Chem. Lett. 9, 2985 (2018).

143. M. Taylor and G.E. Brown, Jr: Structure of mineral glasses I. The feldspar glasses $\mathrm{NaAlSi}_{3} \mathrm{O}_{8}, \mathrm{KAlSi}_{3} \mathrm{O}_{8}, \mathrm{CaAl}_{2} \mathrm{Si}_{2} \mathrm{O}_{8}$. Geochim. Cosmochim. Acta 43, 61 (1979).

144. M. Taylor and G.E. Brown, Jr: Structure of mineral glasses II. The $\mathrm{SiO}_{2}-\mathrm{NaAlSiO}_{4}$ join. Geochim. Cosmochim. Acta 43, 1467 (1979).

145. H. Schlenz, A. Kirfel, K. Schulmeister, N. Wartner, W. Mader, W. Raberg, K. Wandelt, C. Oligschleger, S. Bender, and

R. Franke: Structure analyses of Ba-silicate glasses. J. Non-Cryst. Solids 297, 37 (2002).

146. J.P. Hamilton, C.G. Pantano, and S.L. Brantley: Dissolution of albite glass and crystal. Geochim. Cosmochim. Acta 64, 2603 (2000).

147. J.P. Hamilton, S.L. Brantley, C.G. Pantano, L.J. Criscenti, and J.D. Kubicki: Dissolution of nepheline, jadeite and albite glasses: Toward better models for aluminosilicate dissolution. Geochim. Cosmochim. Acta 65, 3683 (2001).

148. J.P. Icenhower and P.M. Dove: The dissolution kinetics of amorphous silica into sodium chloride solutions: Effects of temperature and ionic strength. Geochim. Cosmochim. Acta 64, 4193 (2000).
149. A. Takada, R. Conradt, and P. Richet: Residual entropy and structural disorder in glass: A review of history and an attempt to resolve two apparently conflicting views. J. Non-Cryst. Solids $\mathbf{4 2 9}$ 33 (2015).

150. R. Conradt: On the entropy difference between the vitreous and the crystalline state. J. Non-Cryst. Solids 355, 636 (2009).

151. A. Perez, D. Daval, M. Fournier, M. Vital, J-M. Delaye, and S. Gin: Comparing the reactivity of glasses with their crystalline equivalents: The case study of plagioclase feldspar. Geochim. Cosmochim. Acta 254, 122 (2019).

152. F. Bouyer, G. Geneste, S. Ispas, W. Kob, and P. Ganster: Water solubility in calcium aluminosilicate glasses investigated by first principles techniques. J. Solid State Chem. 183, 2786 (2010).

153. C.M. Jantzen and K.G. Brown: Predicting the spinel-nepheline liquidus for application to nuclear waste glass processing. Part II: Quasicrystalline freezing point depression model. J. Am. Ceram. Soc. 90, 1880 (2007).

154. R. Hellmann, R. Wirth, D. Daval, J-P. Barnes, J-M. Penisson, D. Tisserand, T. Epicier, B. Florin, and R.L. Hervig: Unifying natural and laboratory chemical weathering with interfacial dissolution-reprecipitation: A study based on the nanometerscale chemistry of fluid-silicate interfaces. Chem. Geol. 294, 203 (2012).

155. S. Gin, P. Jollivet, M. Fournier, F. Angeli, P. Frugier, and T. Charpentier: Origin and consequences of silicate glass passivation by surface layers. Nat. Commun. 6, 6360 (2015).

156. T. Geisler, L. Dohmen, C. Lenting, and M.B.K. Fritzsche: Realtime in situ observations of reaction and transport phenomena during silicate glass corrosion by fluid-cell Raman spectroscopy. Nat. Mater. 18, 342 (2019).

157. E. Ruiz-Agudo, C. Putnis, and A. Putnis: Coupled dissolution and precipitation at mineral-fluid interfaces. Chem. Geol. 383, 132 (2014)

158. T. Geisler, T. Nagel, M.R. Kilburn, A. Janssen, J.P. Icenhower, R.O.C. Fonseca, M. Grange, and A.A. Nemchin: The mechanism of borosilicate glass corrosion revisited. Geochim. Cosmochim. Acta 158, 112 (2015).

159. R. Hellmann, S. Cotte, E. Cadel, S. Malladi, L.S. Karlsson, S. Lozano-Perez, M. Cabié, and A. Seyeux: Nanometre-scale evidence for interfacial dissolution-reprecipitation control of silicate glass corrosion. Nat. Mater. 14, 307 (2015).

160. S. Gin, M. Collin, P. Jollivet, M. Fournier, Y. Minet, L. Dupuy, T. Mahadevan, S. Kerisit, and J. Du: Dynamics of selfreorganization explains passivation of silicate glasses. Nat. Commun. 9, 1 (2018).

161. D. Daval, S. Bernard, L. Rémusat, B. Wild, F. Guyot, J.S. Micha, F. Rieutord, V. Magnin, and A. FernandezMartinez: Dynamics of altered surface layer formation on dissolving silicates. Geochim. Cosmochim. Acta 209, 51 (2017). 
162. R.C.T. Slade, J. Barker, P.R. Hirst, T.K. Halstead, and P.I. Reid: Conduction and diffusion in exchanged montmorillonite clays. Solid State Ionics 24, 289 (1987).

163. R. Beyerlein, G. McVicker, L. Yacullo, and J. Ziemiak: The influence of framework and nonframework aluminum on the acidity of high-silica, proton-exchanged FAU-framework zeolites. J. Phys. Chem. 92, 1967 (1988).

164. M.J. Stephenson, M.P. Attfield, S.M. Holmes, and R.A. Dryfe: Electrochemically controlled ion exchange: Proton ion exchange with sodium zeolite X and A. J. Solid State Electrochem. 19, 1985 (2015).

165. L.P. Knauth: Salinity history of the Earth's early ocean. Nature 395, 554 (1998).

166. L.P. Knauth: Temperature and salinity history of the precambrian ocean: Implications for the course of microbial evolution. In Geobiology: Objectives, Concepts, Perspectives, N. Noffke, ed. (Elsevier Science, 2005); p. 53.

167. C.L. Blättler, J.A. Higgins, and P.K. Swart: Advected glacial seawater preserved in the subsurface of the Maldives carbonate edifice. Geochim. Cosmochim. Acta 257, 80 (2019).

168. W.M. Haynes: CRC Handbook of Chemistry and Physics (CRC Press, Boca Raton, FL, 2014).

169. A. Earnshaw and N.N. Greenwood: Chemistry of the Elements (Butterworth-Heinemann Oxford Oxford, United Kingdom, 1997).

170. K.K. Turekian: Oceans Foundations of Earth Science Series (Prentice-Hall Upper Saddle River, NJ, 1968).

171. P.P. Povinec, H.D. Livingston, S. Shima, M. Aoyama, J. Gastaud, I. Goroncy, K. Hirose, L. Huynh-Ngoc, Y. Ikeuchi, and T. Ito: IAEA'97 expedition to the NW Pacific OceanResults of oceanographic and radionuclide investigations of the water column. Deep-Sea Res. Part II Top. Stud. Oceanogr. 50, 2607 (2003).
172. P. Treguer, D.M. Nelson, A.J. Van Bennekom, D.J. DeMaster, A. Leynaert, and B. Queguiner: The silica balance in the world ocean: A reestimate. Science 268, 375 (1995).

173. P.J. Tréguer and C.L. De La Rocha: The world ocean silica cycle. Annu. Rev. Mar. Sci. 5, 477 (2013).

174. D.P. Calmet: Ocean disposal of radioactive waste. Status report. IAEA Bull. 31, 47 (1989).

175. A.E. Ringwood, S.E. Kesson, N.G. Ware, W. Hibberson, and A. Major: Immobilization of high-level nuclear-reactor wastes in synroc. Nature 278, 219 (1979).

176. F.K. Crundwell: The mechanism of dissolution of minerals in acidic and alkaline solutions: Part II application of a new theory to silicates, aluminosilicates and quartz. Hydrometallurgy 149, 265 (2014).

177. B.R. Bickmore, J.C. Wheeler, B. Bates, K.L. Nagy, and D.L. Eggett: Reaction pathways for quartz dissolution determined by statistical and graphical analysis of macroscopic experimental data. Geochim. Cosmochim. Acta 72, 4521 (2008).

178. F.K. Crundwell: The mechanism of dissolution of minerals in acidic and alkaline solutions: Part I-A new theory of nonoxidation dissolution. Hydrometallurgy 149, 252 (2014).

179. F.K. Crundwell: On the mechanism of the dissolution of quartz and silica in aqueous solutions. ACS Omega 2, 1116 (2017).

180. H.A. Dobbs, G.D. Degen, Z.J. Berkson, K. Kristiansen, A.M. Schrader, T. Oey, G. Sant, B.F. Chmelka, and J.N. Israelachvili: Electrochemically enhanced dissolution of silica and alumina in alkaline environments. Langmuir 35, 15651 (2019).

181. X. Guo, S. Gin, P. Lei, T. Yao, H. Liu, D.K. Schreiber, D. Ngo, G. Viswanathan, T. Li, S.H. Kim, J.D. Vienna, J.V. Ryan, J. Du, J. Lian, and G.S. Frankel: Self-accelerated corrosion of nuclear waste forms at material interfaces. Nat. Mater. 19, 310 (2020). 